\title{
Trade and Insecure Resources ${ }^{\dagger}$
}

\author{
Michelle R. Garfinkel \\ University of California, Irvine \\ Stergios Skaperdas \\ University of California, Irvine \\ Constantinos Syropoulos \\ Drexel University
}

Current Version: September 10, 2013

\begin{abstract}
We construct a model of conflict and trade to study the consequences of interstate disputes over contested resources (land, oil, water or other resources) for arming, welfare and trade flows. Different trade regimes imply different costs of such disputes in terms of arming. Depending on world prices, free trade can intensify arming to such an extent that the additional security costs it brings swamp the traditional gains from trade and thus render autarky more desirable for one or all rival states. Free trade, though, is always an equilibrium, and sometimes is a dominant one with features of a prisoner's dilemma outcome. Furthermore, contestation of resources can reverse a country's apparent comparative advantage relative to its comparative advantage in the absence of conflict. And, where such conflict is present, comparisons of autarkic prices to world prices could be inaccurate predictors of trade patterns.
\end{abstract}

JEL Classification: D30, D70, D72, D74, F2, F10.

Keywords: trade openness, property rights, interstate disputes, conflict, security policies.

\footnotetext{
${ }^{\dagger}$ The authors wish to thank Daron Acemoglu, Eric Bond, Merwan Engineer, Ethan Kapstein, Giovanni Maggi, Michael McBride, Robert Powell, Priya Ranjan, and participants of the CEPR workshop on Conflicts, Globalization and Development, the Yale-Princeton workshop on War and Trade, the Canadian Economics Association Meeting and other venues for helpful comments and suggestions on earlier drafts of this paper.
} 
A country of our size, with its focus on exports and thus reliance on foreign trade, must be aware that military deployments are necessary in an emergency to protect our interests, for example, when it comes to trade routes, for example, [sic] when it comes to preventing regional instabilities that could negatively influence our trade, jobs and incomes.

Horst Köhler, former President of Germany (quoted in NY Times, May 31, 2010)

\section{Introduction}

It is unusual for prominent public officials like the former President of Germany to make such seemingly politically incorrect statements. Military deployments for the protection of a country's own interest and trade routes - instead of, say, the protection of human rights and the promotion of democracy - perhaps sound too crass and cynical for today's international norms. Although Dr. Köhler was forced to resign from the Presidency of Germany for uttering the words quoted above, he did not ultimately disavow his essential belief in them.

Given that the international system is essentially anarchic without the third-party enforcement that usually exists within individual states, economists would not find it controversial to assert that the defense expenditures of countries are related to their perceived interests, such as maintaining access to resources that might be in dispute. After all, as amply demonstrated in Findlay's and O'Rourke's (2007) overview of Eurasia's economic history, military competition for resources and the expansion of world trade were inextricably linked over the whole of the past millennium. While interstate wars have become less common in the post-World War II period than they had been in the thirty years prior to that, there have been both enough of them and, more seriously, enough disputes to keep almost all countries armed. Examples of hot disputes in the postwar period include the Suez Canal crisis in the 1950s, Iraq's invasion of Kuwait that resulted in the first Gulf war in the early 1990s, and the Kashmir dispute between India and Pakistan. Numerous other disputes - from that over the Spratly and Paracel islands in the South China Sea, to disputes over water (e.g., flowing through rivers like the Nile and the Brahmaputra), and to others involving oil, minerals, or simply land - might have not resulted in hot incidents; however, they keep the militaries of almost all countries busy. ${ }^{1}$ The direct and indirect costs of such disputes are large. For example, the latest estimates of the costs of the Iraq and Afghanistan wars to the United States are around 4 to 6 trillion dollars (Stiglitz and Bilmes, 2012).2

\footnotetext{
${ }^{1}$ See, Klare (2001), for an overview and many examples.

${ }^{2}$ Military expenditures alone were about 2.6 percent of world GDP during 2004, varying from less than 1 percent for a few countries to more than 10 percent for Saudi Arabia (SIPRI, 2005). To get some sense of the overall costs of conflict (including civil war), Blomberg and Hess (2012) estimate a lower bound for the yearly cost of conflict of 9 percent of steady state consumption for the 1950 to 2004 period. For high-income
} 
The quantitative importance of security costs naturally raises some questions as to how interstate disputes over resources matter for trade openness and vice versa. More specifically, how do different trade regimes (e.g., autarky and free trade) affect the extent to which productive resources are diverted into arming? Recognizing that security policies themselves are trade-regime dependent, what is the relationship between trade openness and welfare? Is free trade an equilibrium policy? And, if it is, what are its implications for the direction and volume of trade flows?

In general, there are two channels through which trade openness in the presence of insecurity could matter for the allocation of productive resources. First, a switch from autarky to free trade alters product prices and thus factor prices, and thereby influences the relative costs of hiring productive resources for arming purposes. Second, product prices and thus the terms of trade could themselves depend on security policies; this feedback channel would also be relevant for the determination of security policies and more generally the allocation of productive resources.

In this paper, we aim to address the questions identified above, emphasizing the first of these two channels that highlights the role of endogenous factor prices. Specifically, our analysis builds on a modified version of the Heckscher-Ohlin-Samuelson model of trade, focusing on the case of two small countries (i.e., countries having no influence on the world price) that possibly trade with the "rest of the world," which we treat as exogenous. ${ }^{3}$ The model is augmented to allow for insecurity-more precisely, conflict between the two small countries over a resource - and its accompanying costs. The neoclassical model (which we also call the "Nirvana" model, to use Demsetz's (1969) apt term) is a limiting case of our model when security is costless and perfect.

In the model, one factor of production ("labor") is perfectly secure, while the other ("land") is, in part, insecure. The distribution of insecure land between the two countries depends on the relative amount of arming by each. Arming itself is produced with the two factors of production and the cost of its production represents security costs. A key feature of this framework is that it captures the trade-regime dependence of the net marginal benefit of arming and thus of the incentive to arm. With arming endogenous, the factor endowments left over for use in civilian production of the two final goods are also endogenous

countries like the United States and France the cost was roughly 4.5 percent of consumption, whereas for Iraq and Iran, largely as a result of the war between then, it was nearly 77 percent and 16 percent of their respective yearly consumptions.

${ }^{3}$ To be sure, as noted below, we view the large-country case where the second channel comes into play as important. Such an analysis, however, is beyond the scope of the present paper. Nevertheless, in ongoing research, we are exploring the consequences of insecure resources in a Ricardian model with a non-traded goods sector, to capture both factor-price effects and product-price effects. The results in that setting, however, are qualitatively similar to what we find in the present paper that focuses solely on the consequences of factor-price effects. 
and depend on the trade regime prevailing in the two countries. Thus, both security costs and the factor endowments used in civilian production are endogenous to the prevailing trade regime. The two trade regimes we consider and compare are autarky and free trade.

Our comparison of welfare under these two regimes shows that the relative factor intensities of the two civilian goods play an important role. For example, when the countries are identical and they both import the land-intensive good under free trade, free trade is superior to autarky for both countries. In this case, because the good produced intensively with the contested resource can be obtained more cheaply in world markets than it could be produced domestically under autarky, free trade reduces the incentive to arm and thus the security costs relative to the autarkic outcome. Therefore, free trade is better due to both the traditional gains from trade and the lower costs of security. However, when both countries export the land-intensive good, they might very well prefer autarky. In particular, the higher export price compared with the price of the good under autarky makes competition over land more intense, thereby increasing the costs of security. Of course, a higher export price also brings gains from trade. But, for export prices not too high, these gains are outweighed by the increased security costs, to render autarky preferable to free trade.

More generally, the two trading regimes considered imply very different security costs. Under autarky, these costs depend on the domestic factor and goods prices in both countries, whereas under free trade they tend to be equalized across countries because of factor price equalization. Autarky will be preferable for one or both countries when free trade involves higher added security costs relative to the gains from trade.

These results might be taken to imply that adversarial countries would choose to impose barriers to trade for those world prices that make autarky preferable to free trade for both countries. However, an extended analysis of the model to consider the non-cooperative choice of trade regimes by two identical countries shows that free trade is always a subgame perfect equilibrium for such world prices; and, for a subset of those prices, it is the unique, dominant-strategy equilibrium, thus leading to a prisoner's dilemma outcome. By the same token, in the presence of resource insecurity and the absence of institutions to deal with it, "cooperation" in the form of freer trade policies can lead to perverse outcomes and alone cannot address the fundamental problem at hand. That is to say, realizing the gains from free trade requires that we address the problem of resource insecurity.

We also show how resource insecurity induces distortions in resources left for production of traded goods and thus in comparative advantage. It does so in at least two possible ways: (i) by causing trade patterns to differ from the ones that would have emerged under Nirvana; and, (ii) by altering the information content of the difference between free-trade and autarkic prices, and thus possibly leading to erroneous predictions of the direction of trade flows. If, for example, the technology for arming is sufficiently intensive in the 
use of the perfectly secure resource (labor), then insecurity implies relatively less of that resource is left for the production of traded goods. Consequently, the world price of the consumption good employing the secure resource intensively that implies no trade tends to exceed the analogous price that would have prevailed under Nirvana. The net effect is that there exists a range of world prices for which a country is an importer of that consumption good when there is insecurity, whereas it would have been an exporter of the same good under Nirvana. Similarly, because the introduction of free trade in consumption goods alters product and factor prices, arming incentives along with the mix of resources absorbed in arming, and thus the resources left for the production of consumption goods, a country's true comparative advantage (given insecurity) can differ from that which is implied by a simple comparison of autarkic prices to world prices. Both of these distortions imply that the presence of insecurity plays an important role in the determination of a country's actual trade patterns that traditional approaches fail to capture.

Our substantive characterization results do not depend on specific functional forms of production or utility functions. The resulting generalized treatment sets the stage for applications and extensions of the basic model to settings in which insecure property rights figure prominently in world affairs. In particular, such applications and extensions can provide new insight into the relationship between trade and security policies of adversaries and allies, which is of great relevance to the fields of international relations and international political economy.

This paper's contribution is related to literatures in both political science and economics. Political scientists have long been interested in the linkages between international trade and conflict. ${ }^{4}$ Economists, by contrast, have only begun to explore these linkages. Examples include Anderson and Marcouiller (2005) and Anderton et al. (1999), who analyze Ricardian models in which traded goods are insecure either because of the presence of pirates and bandits or because the contending sides influence the terms of trade through arming. Both approaches emphasize the important, though basic, point that international trade can be hampered by the anarchic nature of international relations. Skaperdas and Syropoulos (2001, 2002) address some of the implications of insecure property in the context of simple exchange models. Acemoglu et al. (2012) explore the implications for intertemporal pricing and the exhaustion of a contested resource in a dynamic setting. Martin et al. (2008) also

\footnotetext{
${ }^{4}$ See Barbieri and Schneider (1999), who survey much of the theoretical and empirical literatures on the subject. Many of the analyses, in contrast to ours, emphasize the aggregate income effects of trade, with the gains of trade reflected in higher incomes that tend to amplify incentives to arm. Rowe $(1999,2005)$ is, to our knowledge, the sole political scientist who emphasizes the role of factor endowments. Although he does so in a qualitative fashion (focusing on military costs, while effectively abstracting from the potential benefits of security policies), his analysis of how globalization in the late 1800s and early 1900s set the stage for World War I points to the importance of the mechanism highlighted in our study-namely, the link between product and factor prices that determines the costs of security.
} 
consider the linkages between conflict and international trade, but they take a very different approach, one that abstracts from arming decisions and the endogenous determination of security costs, emphasizing instead the role of expanded multilateral trade opportunities in possibly creating an environment that is more conducive to bilateral conflict.

While extant trade theory has ruled out security problems by assumption, there are some exceptions that focus on the related problem of open-access resources. Chichilnisky (1994) argues that trade can reduce welfare in the South by accentuating the over-exploitation of an open-access resource in which it has a comparative advantage, ${ }^{5}$ and Brander and Taylor (1997a) formally prove this idea. Hotte et al. (2000) also study the effects of trade in an open-access resource and extend the analysis to consider the evolution of private enforcement in dynamic environments. Margolis and Shogren (2002) consider a NorthSouth trade model with enclosures. The key difference between these models and ours is that enforcement costs are due to the active contestation of resources.

In the next section, we present the formal model and a preliminary analysis that proves useful in subsequent sections. In Section 3, we investigate optimal security policies under autarky and free trade. Then, in Section 4, we explore the implications of international conflict for trade patterns and trade volumes. A comparison between autarky and free trade in terms of their implications for security costs and welfare follows in Section 5. Section 6 examines the strategic considerations that come into play in the non-cooperative choice of trade regimes by each country. Lastly, in Section 7, we offer several concluding comments. All technical arguments and proofs have been relegated to the Appendix.

\section{Framework and Preliminary Analysis}

Consider a global economy that consists of two countries, indexed by $i=1,2$, and the rest of the world (ROW), which for simplicity is treated as a single entity and taken as exogenous. Each country can produce two consumption goods (say "butter" and "oil"), indexed by $j=1,2$, using labor and land under constant returns to scale. In the spirit of the Heckscher-Ohlin-Samuelson (HOS) trade model and as a benchmark, we assume the countries have access to the same production technology; consumers have identical and homothetic preferences defined over the two consumption goods; and, all markets are perfectly competitive. Each country $i$ possesses $L^{i}$ units of secure labor and $K^{i}$ units of secure land. However, departing from the HOS trade model, we assume there exists an additional $K_{0}$ units of land. (Of course, what we call land $(K)$ could also be interpreted as a natural resource (e.g., oil, water) or physical capital.) Although this additional land is divisible, its division between the two countries is subject to dispute. Policymakers use arming to gain control of the disputed resource, with the ultimate goal of maximizing

\footnotetext{
${ }^{5}$ Her analysis also points to the importance of open-access resources for the pattern of trade.
} 
national welfare.

\subsection{Introducing conflict}

Let country $i$ 's "guns" be denoted by $G^{i}$, a variable most accurately viewed as a producible composite good that reflects country $i$ 's military capability. Country $i$ 's share of $K_{0}$, then, is determined by the following contest success function (or technology of conflict):

$$
\phi^{i}\left(G^{i}, G^{j}\right)=\left\{\begin{array}{lll}
\frac{f\left(G^{i}\right)}{f\left(G^{1}\right)+f\left(G^{2}\right)} & \text { if } & \sum_{i=1,2} G^{i}>0 \\
\frac{1}{2} & \text { if } & \sum_{i=1,2} G^{i}=0
\end{array}\right.
$$

for $i=1,2(j \neq i)$, where $f(\cdot) \geq 0, f(0)=0, f^{\prime}(\cdot)>0, \lim _{G^{i} \rightarrow 0} f^{\prime}\left(G^{i}\right)=\infty$, and $f^{\prime \prime}(\cdot) \leq 0 .{ }^{6}$ According to $(1)$, the fraction of the disputed resource a country secures in the contest depends on its own guns as well as those of its adversary. Specifically, it is increasing in the country's own guns $\left(\phi_{G^{i}}^{i} \equiv \partial \phi^{i} / \partial G^{i}>0\right)$ and decreasing in the guns of its adversary $\left(\phi_{G^{j}}^{i} \equiv \partial \phi^{i} / \partial G^{j}<0, j \neq i\right)$. The influence of guns on a country's share, $\phi^{i}\left(G^{i}, G^{j}\right)$, could be taken literally or viewed as the reduced form of a bargaining process, in which relative arming figures prominently in the division of the contested resource. ${ }^{7}$ In any case, each country has an incentive to produce guns, whereby it can obtain a larger share of the contested land and thus more income. But, there is an opportunity cost of doing so - namely, the loss in income due to the diversion of resources away from the production of consumption goods. This trade-off, which is trade-regime dependent, plays an important role in the determination of the countries' security policies. ${ }^{8}$

The setting here is an anarchic one, so that writing enforceable (binding) contracts on the proliferation of arms and the division of $K_{0}$ is not possible. Instead, we view guns as the "enforcement" variable that determines each country's share of the contested resource,

\footnotetext{
${ }^{6}$ In the Appendix we derive some useful properties of this specification. The condition that $\lim _{G^{i} \rightarrow 0} f^{\prime}\left(G^{i}\right)=\infty$ and the assumed concavity of $f(\cdot)$ help establish existence and uniqueness of equilibrium in the interior of the strategy space (see the proof to Theorem A.1 in the Appendix). Skaperdas (1996) axiomatizes (1), requiring only that $f(\cdot)$ is a non-negative, increasing function. One functional form for $f(\cdot)$ that has been widely used in the rent-seeking literature, as well as in the literatures on tournaments and conflict, is $f(G)=G^{\gamma}$ where $\gamma \in(0,1]$ (Tullock, 1980). See Hirshleifer (1989) for a comparison of the properties of this form with those of $f(G)=e^{\gamma G}$. As noted below, employing alternative specifications for $\phi^{i}\left(G^{i}, G^{j}\right)$ that allow for either non-additivity or asymmetry would not change the results to follow. For a more general analysis of the comparative static results of conflict, see Acemoglu and Jensen (2011).

${ }^{7}$ See Anbarci et al. (2002) for an analysis of this issue and how, in particular, different bargaining solution concepts lead to division rules that vary in their sensitivity to guns.

${ }^{8}$ While countries often build their own militaries, they can, in practice, also buy or sell certain weapons in the world market, as well as hire mercenaries or foreign security experts. The analysis could easily be extended to allow for the international trade of guns. In particular, viewing "guns" as a composite good produced according to a linearly homogenous function with weapons and soldiers as its arguments, the link between product (and arms) prices and factor prices would remain, so that our main insights would go through. However, to highlight how pure trade in goods affects arming incentives, we abstract from such possibilities in this analysis.
} 
which in turn can be combined with the country's remaining secure endowments of labor and land to produce consumption goods. Accordingly, the sequence of events is as follows:

(i) Given the initial distribution of secure factor endowments $\left(L^{i}\right.$ and $\left.K^{i}\right)$, the two countries $(i=1,2)$ simultaneously choose their production of guns $G^{i}$.

(ii) Once these choices are made, the contested land is divided according to (1): each country $i$ receives $\phi^{i} K_{0}$ units of the contested resource.

(iii) With the quantities of land and labor left for the production of consumption goods having thus been determined, private production and consumption decisions take place. Under autarky, prices adjust to clear domestic markets. Under free trade, the prices of consumption goods are fixed in the world market.

A conflictual equilibrium is the Nash equilibrium in guns, conditional on the prevailing trade regime.

To complete the basic model, we now specify the supply and demand sides of each economy.

\subsection{Production}

Starting with the supply side, let $\psi^{i} \equiv \psi\left(w^{i}, r^{i}\right)$ and $c_{j}^{i} \equiv c_{j}\left(w^{i}, r^{i}\right)$ represent respectively the unit cost functions of guns and goods $j=1,2$ in country $i$, where $w^{i}$ and $r^{i}$ denote competitively determined factor prices - respectively, the wage paid to labor and the rental rate paid to landowners. These unit cost functions have the usual properties, including concavity and linear homogeneity in factor prices. By Shephard's lemma, the unit land and labor requirements in arms production are given respectively by $\psi_{r}^{i} \equiv \partial \psi^{i} / \partial r^{i}>0$ and $\psi_{w}^{i} \equiv \partial \psi^{i} / \partial w^{i}>0$. Similarly, $a_{K j}^{i} \equiv \partial c_{j}^{i} / \partial r^{i}>0$ and $a_{L j}^{i} \equiv \partial c_{j}^{i} / \partial w^{i}>0$ represent the unit land and labor requirements in producing good $j$. Therefore, the land-labor ratio in guns is $k_{G}^{i} \equiv \psi_{r}^{i} / \psi_{w}^{i}$, and the corresponding ratio in industry $j$ is $k_{j}^{i} \equiv a_{K j}^{i} / a_{L j}^{i}$. Industry 2 is land intensive if $k_{2}^{i}>k_{1}^{i}$ (or labor intensive if $k_{2}^{i}<k_{1}^{i}$ ) at all relevant factor prices. (We follow much of the literature based on the HOS trade model in ruling out factor intensity reversals.) Although we will show how the ranking of factor intensities across industries $j=1,2$ matters, for specificity we emphasize throughout much of the discussion the case where good 2 is produced intensively with the insecure resource (i.e., land).

Taking good 1 as the numeraire, let $p^{i}$ denote the relative price of good 2 in country $i$. Perfect competition requires zero profits, or assuming diversification in production,

$$
\begin{aligned}
& c_{1}\left(w^{i}, r^{i}\right)=a_{L 1}^{i} w^{i}+a_{K 1}^{i} r^{i}=1 \\
& c_{2}\left(w^{i}, r^{i}\right)=a_{L 2}^{i} w^{i}+a_{K 2}^{i} r^{i}=p^{i},
\end{aligned}
$$


for $i=1,2$. These equations, together with the assumption of identical technologies across countries and the properties of unit cost functions, imply that the wage-rental ratio, $\omega^{i} \equiv$ $w^{i} / r^{i}$, can be written as a function of the relative price (i.e., $\left.\omega^{i}=\omega\left(p^{i}\right)\right)$. By the StolperSamuelson (1941) theorem, a rise in $p^{i}$ increases the return to that factor which is used intensively in the production of good 2 , and at the same time decreases the return to the other factor: $\omega_{p}^{i}\left(\equiv \partial \omega / \partial p^{i}\right) \lessgtr 0$ as $k_{2}^{i} \gtrless k_{1}^{i}$ (see Lemma A.1(a) in the Appendix).

Let $\left(K_{X}^{i}, L_{X}^{i}\right)$ denote the vector of residual quantities of resources left for the production of consumption goods in country $i$ at the end of stage (ii), once labor and land resources have already been employed in the production of guns $G^{i}$, respectively $\psi_{w}^{i} G^{i}$ and $\psi_{r}^{i} G^{i}$, and the distribution of the contested resource has been realized, $\phi^{i} K_{0}$. Furthermore, let $X_{j}^{i}$ denote country $i$ 's output of good $j$. Then, factor-market clearing and diversification in production require in each country $i$,

$$
\begin{aligned}
a_{K 1}^{i} X_{1}^{i}+a_{K 2}^{i} X_{2}^{i} & =K_{X}^{i} \quad\left(\equiv K^{i}+\phi^{i} K_{0}-\psi_{r}^{i} G^{i}\right) \\
a_{L 1}^{i} X_{1}^{i}+a_{L 2}^{i} X_{2}^{i} & =L_{X}^{i} \quad\left(\equiv L^{i}-\psi_{w}^{i} G^{i}\right) .
\end{aligned}
$$

Now, let $k_{X}^{i}$ denote country $i$ 's residual land-labor ratio:

$$
k_{X}^{i} \equiv \frac{K_{X}^{i}}{L_{X}^{i}}=\frac{K^{i}+\phi^{i} K_{0}-\psi_{r}^{i} G^{i}}{L^{i}-\psi_{w}^{i} G^{i}}, \text { for } i=1,2
$$

Then, it is straightforward to verify, from (4) and (5) along with the linear homogeneity of unit cost functions and the fact that $\omega^{i}=\omega\left(p^{i}\right)$, that the relative supply of good 2 (oil), $R S^{i} \equiv X_{2}^{i} / X_{1}^{i}$, can be written as $R S^{i}=R S\left(p^{i}, k_{X}^{i}\right)$. In the Appendix (Lemma A.1(b)) we show that the relative supply of good 2 is increasing in its relative price, due to increasing opportunity costs: $\partial R S^{i} / \partial p^{i}>0$. In addition, Lemma A.1(c) establishes, consistent with the Rybczynski (1955) theorem, that an exogenous increase in the residual land-labor ratio causes an increase in the relative supply of the good that uses land intensively: $\partial R S^{i} / \partial k_{X}^{i} \gtrless$ 0 as $k_{2}^{i} \gtrless k_{1}^{i}$. Of course, as can be seen from (6) keeping in mind that $\omega^{i}=\omega\left(p^{i}\right)$, the residual land-labor ratio itself is endogenously determined, and can be written as a function of the relative price of good 2, the guns produced by the two countries, and resource endowments. To avoid cluttering of notation, we write this function as $k_{X}^{i}=k_{X}^{i}\left(p^{i}, G^{i}, G^{j}\right)$. Lemma A.2 in the Appendix describes the dependence of $k_{X}^{i}$ on its arguments. At this point, it is only important to recognize the implication that the relative supply of good 2 can also be written as a function of the price and guns: $R S^{i}=R S\left(p^{i}, G^{i}, G^{j}\right)$. In the next section, we characterize the exact nature of this relationship, as needed in the identification of market-clearing prices and in the analysis of conflict under autarky. 


\subsection{Payoffs}

Turning to the demand side, let $R^{i}$ denote net national income and $\mu^{i} \equiv \mu\left(p^{i}\right)$ denote the marginal utility of income. Country $i$ 's indirect utility (aggregate welfare) function can then be written as $^{9}$

$$
V^{i} \equiv V^{i}\left(p^{i}, G^{i}, G^{j}\right)=\mu\left(p^{i}\right) R^{i}\left(p^{i}, K_{X}^{i}, L_{X}^{i}\right), \text { for } i=1,2(j \neq i)
$$

Equation (7) implicitly assumes that policymakers finance the cost of arming with nondistortionary income taxes. This assumption, together with that of perfect competition, implies that country $i$ 's net national income $\left(R^{i}\right)$ is the country's maximized value of domestic production of consumption goods and, at the same time, the minimized value of rental payments paid to residual labor and land owners. Then, equations (2)-(5) imply $R^{i}=X_{1}^{i}+p^{i} X_{2}^{i}=r^{i} K_{X}^{i}+w^{i} L_{X}^{i}$ for $i=1,2$, which explains the arguments of $R^{i}$ and $V^{i}$ in (7). $R^{i}$ should be identified with the familiar gross domestic product (GDP) or revenue function (Dixit and Norman, 1980), excluding arms expenditures. As one can verify, $R^{i}$ is increasing and convex in $p^{i}$, and the supply of good 2 satisfies $X_{2}^{i}=R_{p}^{i}\left(\equiv \partial R^{i} / \partial p^{i}\right)$, where $\partial X_{2}^{i} / \partial p^{i}=R_{p p}^{i} \geq 0 .{ }^{10}$

Using Roy's identity, country $i$ 's demand function for good 2 can be written as $D_{2}^{i}=$ $\alpha_{D}^{i} R^{i} / p^{i}$, where the associated expenditure share is given by $\alpha_{D}^{i} \equiv \alpha_{D}\left(p^{i}\right)=-p^{i} \mu_{p}^{i} / \mu^{i}$ $(>0)$. Therefore, the excess demand for (or net imports of) good 2 is given by $M^{i} \equiv D_{2}^{i}-X_{2}^{i}$, where $X_{2}^{i}=R_{p}^{i}$.

Then, holding fixed the secure resource endowments $\left(K^{i}\right.$ and $\left.L^{i}\right)$ as well as the disputed resource $\left(K_{0}\right)$, total differentiation of $(7)$ yields

$$
d V^{i}=\mu\left(p^{i}\right)\left[-M^{i} d p^{i}+\left(r^{i} K_{0} \phi_{G^{i}}^{i}-\psi^{i}\right) d G^{i}+r^{i} K_{0} \phi_{G^{j}}^{i} d G^{j}\right] \quad \text { for } i=1,2(j \neq i)
$$

The first term inside the square brackets, weighted by the marginal utility of income $\mu\left(p^{i}\right)$, is a terms of trade effect. For net importers of good $2\left(M^{i}>0\right)$, an increase in $p^{i}$ increases the domestic cost of good 2, and is thus welfare-reducing. By contrast, a price increase is welfare-improving for net exporters of good $2\left(M^{i}<0\right)$.

The second term in the brackets (weighted by $\mu\left(p^{i}\right)$ ) captures the welfare effect of a change in country $i$ 's guns, $G^{i}$. Ceteris paribus, an increase in $G^{i}$ increases country $i$ 's share of the contested land and thus its national income (the first term inside the parentheses). At the same time, however, the increase in $G^{i}$ draws additional resources away from the production of consumption goods and thus reduces national income (the second term).

\footnotetext{
${ }^{9}$ In this expression, we suppress the obvious dependence of $V^{i}$ on resource endowments to avoid cluttering.

${ }^{10}$ One can also show that $R^{i}$ is increasing and concave in the residual factor inputs $\left(K_{X}^{i}, L_{X}^{i}\right)$ and that factor prices satisfy $w^{i}=R_{L}^{i}\left(\equiv \partial R^{i} / \partial L_{X}^{i}\right)$ and $r^{i}=R_{K}^{i}\left(\equiv \partial R^{i} / \partial K_{X}^{i}\right)$.
} 
The third term in the brackets (again weighted by $\mu\left(p^{i}\right)$ ) captures the welfare effect of a change in arms by country $i$ 's opponent, $G^{j}$. An increase in $G^{j}$ reduces country $i$ 's share of the contested resource and thus its income, and thereby adversely affects that country. Note that, for fixed product prices, an equi-proportionate expansion of both countries' guns, where $G^{1}=G^{2}$ initially, implies no change in the division of the contested land, while increasing the resource cost of guns, and thus necessarily leaves both countries worse off.

\subsection{Incentives for arming}

We now demonstrate how the above ideas inform the derivation of the optimizing security policies (arming) under alternative trade regimes. A key feature of the optimization problem for each country $i$ 's arming choice $G^{i}$ (given $G^{j}$ ) is that, with diversification in production, the corresponding first-order condition (FOC), given by

$$
V_{G^{i}}^{i}\left(p^{i}, G^{i}, G^{j}\right)=\mu\left(p^{i}\right) r^{i}\left[K_{0} \phi_{G^{i}}^{i}-\psi^{i} / r^{i}\right]=0 \text { for } i=1,2(j \neq i)
$$

is the same in form regardless of the trade regime in place. ${ }^{11}$ Under autarky, domestic product market clearing requires $p^{i}$ to adjust so that $M^{i}=0$. This requirement implies that the first term inside the brackets in (8) vanishes, thereby yielding (9) as the relevant FOC. Under free trade in consumption goods, product prices are invariant to security policies for "small" countries; thus, the first term also vanishes under this trade regime.

Equation (9) shows that country $i$ 's net marginal payoff from arming consists of two key components: (i) the marginal benefit of producing guns, which is given by $M B^{i} \equiv K_{0} \phi_{G^{i}}^{i}$ when measured in land units; and (ii) the marginal cost of producing guns, which is given by $M C^{i} \equiv \psi^{i} / r^{i}$ (again measured in land units). Lemma A.3 establishes some important properties of both of these components and thus of the net marginal payoff from arming, particularly their dependence on arming by both countries and on the relative price.

For now, observe from the specification of the conflict technology (1) - and in particular the assumed concavity of $f\left(G^{i}\right)$,- that $M B^{i}$ is decreasing in $i$ 's guns $\left(G^{i}\right)$ given the guns chosen by its rival $\left(G^{j}\right)$, as illustrated in Fig. 1. ${ }^{12}$ Furthermore, $M B^{i}$ rises or falls with $G^{j}$ (i.e., $M B^{i}$ in Fig. 1 shifts up or down) depending on whether country $i$ or $j$ initially produces more guns. But, since changes in the relative price $p^{i}$ (given $G^{i}$ and $G^{j}$ ) have no influence on $M B^{i}$, the marginal benefit is independent of the trade regime in place.

By contrast, $M C^{i}$ does depend on $p^{i}$ through factor prices. In particular, the linear

\footnotetext{
${ }^{11}$ Our discussion here and to follow is based on the assumption that, under both trade regimes, the distribution of factor endowments between the adversaries is such that their production of arms is not constrained by their secure land holdings. We assume further that, under free trade, technology, the distribution of factor endowments, the quantity of the contested resource and the world price are such that production of consumption goods is diversified.

${ }^{12}$ In addition, from equation (A.1), the condition that $\lim _{G^{i} \rightarrow 0} f^{\prime}\left(G^{i}\right)=\infty$ implies $\lim _{G^{i} \rightarrow 0} M B^{i}=\infty$.
} 
homogeneity of the unit cost function of guns $\left(\psi^{i}=\psi\left(w^{i}, r^{i}\right)\right)$ implies that the marginal cost of arming can be written as a function of the wage-rental ratio, $\omega^{i} \equiv w^{i} / r^{i}: M C^{i}=$ $\psi^{i} / r^{i}=\psi\left(\omega^{i}, 1\right)$. Since the unit labor requirement in the production of guns $\left(\psi_{w}^{i}\right)$ is positive, $M C^{i}$ is increasing in $\omega^{i}$. Accordingly, an increase in the price of the good that uses land intensively, which by the Stolper-Samuelson theorem causes $\omega^{i}$ to fall, results in a decrease in the marginal cost of arming. Thus, $M C^{i}$ is decreasing in $p^{i}$ if good 2 is land intensive, and otherwise is increasing in $p^{i}$. But, either way, the mere influence of product prices on $M C^{i}$ implies that the relationship between a country's marginal cost and its arming is trade-regime dependent. Under free trade when production is diversified, the world price alone determines the wage-rental ratio, $\omega^{i}$. Since $\omega^{i}$ is invariant to changes in $G^{i}$, so is the marginal cost of arming, as illustrated by $M C_{F}^{i}$ (the dotted line) in Fig. 1. Under autarky, a country's product and factor prices are endogenously determined along with its choice of guns. In the next section, we show that a country's marginal cost of arming under this regime is generally increasing in its own guns, as depicted by $M C_{A}^{i}$ in Fig. 1.

\section{Trade Regimes and Insecurity}

Building on the results above, we now explore the implications of autarky and free trade for arming. The central objective here is to characterize how the trade regime in place influences arming incentives. We differentiate between trade regimes with subscripts " $A$ " for autarky and " $F$ " for free trade.

\subsection{Autarky}

The first-order conditions in (9) show that, regardless of the trade regime in place, the two countries' optimizing choices for guns $\left(G^{i *}\right.$ for $\left.i=1,2\right)$ depend on the factor prices and thus the product prices prevailing in the respective country, $p^{i}$. Thus, to close the model we need an additional condition, one for each country $i$, that determines the autarkic price, $p_{A}^{i}$ (for $i=1,2$ ). These conditions require domestic markets to clear: $M_{A}^{i}=0$ or equivalently,

$$
R D\left(p^{i}\right)=R S\left(p^{i}, k_{X}^{i}\left(p^{i}, G^{i}, G^{j}\right)\right) \text { for } i=1,2, j \neq i
$$

where $R D\left(p^{i}\right)$ denotes the relative demand for good 2. While the demand for good 2 , as noted above, is given by $D_{2}^{i}=\alpha_{D}^{i} R^{i} / p^{i}$, the demand for good 1 is $D_{1}^{i}=\left(1-\alpha_{D}^{i}\right) R^{i}$;

therefore, the relative demand for good 2 is $R D\left(p^{i}\right) \equiv D_{2}^{i} / D_{1}^{i}=\frac{1}{p^{i}} \frac{\alpha_{D}\left(p^{i}\right)}{1-\alpha_{D}\left(p^{i}\right)}$. One can show that $R D\left(p^{i}\right)$ is uniquely determined by and decreasing in the relative price of good $2, p^{i}$. In addition, as noted above, the relative supply of good $2\left(R S^{i}\right)$ is increasing in $p^{i}$.

Using (10), Lemma A.4 presented in the Appendix shows how the equilibrium price is influenced by changes in the residual land-labor ratio $\left(k_{X}^{i}\right)$ induced by exogenous changes 
in guns and resource endowments. Most importantly for our purposes here, part (a) of the lemma implies that a country's marginal cost of arming under autarky, $M C_{A}^{i}=\psi\left(\omega\left(p_{A}^{i}\right), 1\right)$, is increasing in the country's own guns regardless of the ranking of factor intensities in the consumption goods industries. The logic here is as follows. In the neighborhood of the optimum implicitly defined by (9), an increase in $G^{i}$ (given $G^{j}$ ) raises country $i$ 's residual land-labor ratio (see Lemma A.2(b)). By the Rybczynski theorem, this increase translates into an increase in the relative supply of the good produced intensively with land, causing the relative price of that good to fall-i.e., $\partial p_{A}^{i} / \partial k_{X}^{i} \lessgtr 0$ as $k_{2}^{i} \gtrless k_{1}^{i}$. Whether good 2 or good 1 is produced intensively with land, the Stolper-Samuelson theorem implies, in turn, that the resulting price adjustment will force the wage-rental ratio $\omega^{i}$ to rise and thus induce $M C_{A}^{i}$ to rise with $G^{i}$, as Fig. 1 shows. Noting that an increase in the opponent's arming $G^{j}$ (given $G^{i}$ ) decreases country $i$ 's residual land-labor ratio, one can apply analogous reasoning to part (b) of the lemma to establish that a country's marginal cost of arming is negatively related to the opponent's arming.

Obviously, the intersection of $M C_{A}^{i}$ with $M B^{i}$, such as at point $A$ in Fig. 1, gives country $i$ 's best-response function under autarky, $B_{A}^{i}\left(G^{j}\right)$. The shape of this function depends on how both the marginal cost and marginal benefit functions are influenced by the rival's arming, $G^{j}$. Of course, as we have just seen, $M C_{A}^{i}$ is negatively related to $G^{j}$ and $M B^{i}$ is increasing in $G^{j}$ when $G^{i}>G^{j}$ and decreasing in $G^{j}$ when $G^{i}<G^{j}$. Thus, as illustrated with solid-line curves in Fig. 2, $B_{A}^{i}\left(G^{j}\right)$ depends positively on $G^{j}$ (reflecting strategic complementarity) up to and beyond its point of intersection with the $45^{\circ}$ line; however, at some point beyond that intersection, the function can become negatively related to $G^{j}$ (reflecting strategic substitutability).

One can show, under fairly general circumstances, that an interior Nash equilibrium in pure strategies (security policies) exists in the autarkic trade regime and that it is unique. ${ }^{13}$ The conflictual (Nash) equilibrium under autarky is depicted by the intersection of the two countries' best-response functions. ${ }^{14}$ One such equilibrium - a symmetric one - is point $A$ in Fig. 2, where $B_{A}^{1}$ and $B_{A}^{2}$ intersect along the $45^{\circ}$ line. Point $A^{\prime}$ (where $B_{A}^{1 \prime}$ and $B_{A}^{2 \prime}$ intersect) shows an asymmetric equilibrium.

\footnotetext{
${ }^{13}$ As shown in the proof, which is presented in the Appendix, uniqueness of equilibrium is ensured if either the technology for arms is not very land intensive or if the inputs to arms are not very close complements. These conditions, which are sufficient but not necessary, serve to limit the responsiveness of each contender's security policy to the opponent's guns choice. We should add that the proof is based on the assumption that not all secure land supplies are absorbed into the production of guns. Although this assumption is made for convenience and could be relaxed, we maintain it for clarity. One sufficient condition that precludes the violation of this assumption is that the degree of land insecurity (i.e., the fraction of contested land) is not too high. Another possible condition is that guns are produced with labor only. (Note that, provided that both factors are essential to the production of consumption goods, labor will never be fully absorbed in the production of guns in the autarkic regime.)

${ }^{14}$ Note that, because each country always has an incentive to produce a small (but positive) quantity of arms when its rival produces none, $(0,0)$ is not a Nash equilibrium.
} 
Whether the autarkic equilibrium is symmetric or asymmetric depends on the technologies for producing consumption goods, the technology of conflict (1), the degree of resource insecurity (institutions), and the size of the secure endowments of land and labor, as each influences autarkic prices and thus the marginal cost of arming. To proceed, consider first the benchmark case, where countries 1 and 2 have identical secure endowments. We differentiate the resulting symmetric equilibrium values from others, by placing a tilde $(\sim)$ over the associated variables. Since the countries are identical, they face identical arming incentives; therefore, $G_{A}^{i *}=\widetilde{G}_{A}^{*}$ for $i=1,2$, with each country thus receiving one half of the contested resource, $K_{0}$. Not surprisingly, then, equilibrium product prices and thus factor prices as well as the residual land-labor ratios are also the same across countries: $p_{A}^{i *}=\widetilde{p}_{A}^{*}$, $\omega_{A}^{i *}=\widetilde{\omega}_{A}^{*}$ and $k_{X}^{i *}=\widetilde{k}_{X}^{*}$ for each $i$.

For the results to follow, it is useful to distinguish between two distinct sets of secure endowments of land and labor that differ in their predictions for the relative amounts of arms the two countries produce under autarky: $\mathcal{S}^{0}$ denotes the set of secure endowment distributions implying a symmetric solution such that $G_{A}^{* 1}=G_{A}^{* 2}=\widetilde{G}_{A}^{*}$, and $\mathcal{S}^{i}$ denotes the set of secure endowment distributions implying an asymmetric outcome such that $G_{A}^{* i}>G_{A}^{* j}$ $(j \neq i)$. Clearly, $\mathcal{S}^{0}$ includes the benchmark case where the two countries have identical secure endowments. The next lemma establishes that $\mathcal{S}^{0}$ includes other distributions as well, and it characterizes equilibrium prices and the residual land-labor ratios for distributions in both $\mathcal{S}^{0}$ and $\mathcal{S}^{i}$.

Lemma 1 (Arming and Autarkic Prices) Under autarky, there exists a non-empty set of asymmetric factor distributions under which contending states face identical market-clearing prices, produce identical quantities of arms, and are equally powerful. All other asymmetric distributions generate different prices and unequal arming and power. Specifically, for each country $i=1,2 \quad(j \neq i)$,

(a) $G_{A}^{i *}=\widetilde{G}_{A}^{*}$ and $p_{A}^{i *}=\widetilde{p}_{A}^{*}$ for secure factor distributions in $\mathcal{S}^{0}$, where $k_{X}^{i *}=\tilde{k}_{X}^{*}$;

(b) $G_{A}^{i *}>G_{A}^{j *}$ and $p_{A}^{i *} \gtrless p_{A}^{j *}$ as $k_{2}^{i} \gtrless k_{1}^{i}$ for secure factor distributions in $\mathcal{S}^{i}$, where $k_{X}^{i *}<k_{X}^{j *}$

To see what other distributions, aside from the symmetric one, yield the symmetric outcome, suppose that, starting from the benchmark case, both land and labor resources are transferred from country 2 to country 1 , such that $\left.\frac{d k_{X}^{i}}{k_{X}^{i}}\right|_{d G^{i}=d p^{i}=0}=\frac{d K^{i}}{K_{X}^{i}}-\frac{d L^{i}}{L_{X}^{i}}=0$, which requires $\frac{d K^{i}}{d L^{i}}=\frac{K_{X}^{i}}{L_{X}^{i}}=\widetilde{k}_{X}^{*}$ for each $i$. By construction, such a redistribution of resources, for constant guns and prices, leaves the value of country $i$ 's residual land-labor ratios unchanged at $k_{X}^{i}=\widetilde{k}_{X}^{*}, i=1,2$. Thus, the countries' relative supply and relative demand functions do not shift; and, there is no pressure for autarkic prices to change. But, given prices do, in fact, remain fixed at $\widetilde{p}_{A}^{*}$, arming incentives remain unchanged in both countries. Thus, $\mathcal{S}^{0}$ consists of all secure resource distributions implying the same residual land-labor ratio 
as that for two identical countries, $k_{X}^{1 *}=k_{X}^{2 *}=\widetilde{k}_{X}^{*}$. They all imply the same symmetric outcome. $^{15}$

To see how $\mathcal{S}^{0}$ differs from $\mathcal{S}^{i}$, the set of secure resource endowments implying an asymmetric outcome such that $G_{A}^{* i}>G_{A}^{* j}$, consider an initial secure resource distribution in $\mathcal{S}^{0}$. For such a distribution, the conflictual equilibrium is initially on the $45^{\circ}$ line of Fig. 2 , at point $A$, where $B_{A}^{1}$ and $B_{A}^{2}$ intersect. Now arbitrarily transfer labor only to country 1 from country 2, implying that country 1's residual land-labor ratio falls, while that of country 2 rises. Thus, the price of the good produced intensively with land rises in country 1 and falls in country 2. To fix ideas, suppose good 2 is produced intensively with land (i.e., $\left.k_{2}^{i}>k_{1}^{i}\right)$. Then, the transfer of labor to country 1 increases $p_{A}^{1}$, which in turn decreases its wage-rental ratio and thus its marginal cost of arming; at the same, country 2's loss of labor reduces $p_{A}^{2}$, and thus increases its marginal cost of arming. In this case, since the marginal benefit of arming is independent of the price, country 1 will behave more aggressively, while country 2 will behave less aggressively, as shown in Fig. 2 by the clockwise rotation of $B_{A}^{1}$ to $B_{A}^{1^{\prime}}$ and that of $B_{A}^{2}$ to $B_{A}^{2^{\prime}}$. The uniqueness of equilibrium ensures that the intersection of the new best response functions, $B_{A}^{1^{\prime}}$ and $B_{A}^{2^{\prime}}$, lies below the $45^{\circ}$ line, such as point $A^{\prime}$ in the figure, where clearly country 1 arms more heavily than its adversary. As confirmed in the proof (presented in the Appendix), this effect on the countries' arming incentives holds regardless of the ranking of factor intensities of the two consumption goods. But, this ranking does matter for the ranking of their autarkic prices. Specifically, as suggested by the discussion above, the autarkic price of the good produced intensively with land is higher in the more aggressive country - that is, $G^{1 *}>G^{2 *}$ implies $p_{A}^{1 *}>p_{A}^{2 *}$ when $k_{2}^{i}>k_{1}^{i}$ and $p_{A}^{1 *}<p_{A}^{2 *}$ when $k_{2}^{i}<k_{1}^{i} \cdot{ }^{16}$ This difference in autarkic prices across countries $i=1,2$ allows us to distinguish further $\mathcal{S}^{1}$ from $\mathcal{S}^{0}$. Recall that, for distributions of secure endowments in $\mathcal{S}^{0}, k_{X}^{1 *}=k_{X}^{2 *}=\widetilde{k}_{X}^{*}$. By contrast, since the equilibrium price of the good that is produced intensively with land is decreasing in the residual land-labor ratio, we have $k_{X}^{1 *}<k_{X}^{2 *}$ for distributions in $\mathcal{S}^{1}$ regardless of the ranking of factor intensities across industries. ${ }^{17}$

\footnotetext{
${ }^{15}$ Notice that the logic of this experiment remains intact for numerous conflict technologies, including those that permit non-additivity but maintain symmetry and some that permit asymmetry such as that axiomatized by Clark and Riis (1998): $\phi^{1}\left(G^{1}, G^{2}\right)=\varphi f\left(G^{1}\right) /\left[\varphi f\left(G^{1}\right)+(1-\varphi) f\left(G^{2}\right)\right]$ and $\phi^{2}\left(G^{1}, G^{2}\right)=$ $1-\phi^{1}\left(G^{1}, G^{2}\right)$, where $\varphi \in(0,1)$. In the presence of a more general sort of asymmetry, guns need not be equalized even when secure endowments are identical, but their values will not change from the benchmark case with transfers of secure land and labor that imply $k_{X}^{i}=\widetilde{k}_{X}^{*}$.

${ }^{16}$ See Lemma A.5 in the Appendix for a formal proof of these equilibrium relationships.

${ }^{17}$ See Lemma A.4. For distributions in $\mathcal{S}^{1}$ adjacent to $\mathcal{S}^{0}$, we have $k_{X}^{1 *}<\widetilde{k}_{X}^{*}<k_{X}^{2 *}$, as implied by the proof to Lemma A.6 in the Appendix.
} 


\subsection{Free trade}

Turning to trade, we suppose the contending countries are "small" in world markets and that there are no trade costs. Letting $\pi$ denote the international price of the non-numeraire good, free trade in consumption goods requires $p^{i}=\pi$, for $i=1,2$. Since $\pi$ is given by world markets and is thus independent of national security policies, a country's payoff function can be identified with its indirect utility function, $V^{i}$, as shown in (7) where $p^{i}=\pi$. Depending on fundamentals, the degree of land insecurity, and the international price level, it is possible, as in the case of autarky, for arms production to be constrained by the countries' secure land holdings. ${ }^{18}$ However, it is also possible now for one or both countries to specialize completely in the production of one consumption good. But, to highlight the factor-price effects of opening borders up to free trade and the striking implications this can have for arming incentives, we abstract from these two possible complications.

One can show that when (i) free trade in consumption goods leads to international factor price equalization, and (ii) the production of arms does not exhaust either country's secure land endowment, an interior Nash equilibrium in security policies will exist, and will be unique and symmetric. Here we focus on the logic underlying the symmetric feature of the free-trade equilibrium. ${ }^{19}$

Suppose for now that the two countries have identical secure resource endowments, and that the world price equals the equilibrium price that would obtain in each country if there were no trade: $\pi=\widetilde{p}_{A}^{*}$. Provided conditions (i) and (ii) stated above are satisfied, the intersection of $M B^{i}$ and $M C_{F}^{i}$ (as illustrated in Fig. 1 at point $A$ ) determines country $i$ 's best-response under free trade, $B_{F}^{i}\left(G^{j} ; \widetilde{p}_{A}^{*}\right)$. Since product and thus factor prices are independent of either country's security policy in this trade regime, the shapes of best-response functions are determined solely by the properties of the conflict technology (1), $\phi^{i}$ - that is, $\partial B_{F}^{i} / \partial G^{j}=-V_{G^{i} G^{j}}^{i} / V_{G^{i} G^{i}}^{i}=-\phi_{G^{i} G^{j}}^{i} / \phi_{G^{i} G^{i}}^{i} \gtrless 0$ when $G^{i} \gtrless G^{j}$. Thus, as illustrated in Fig. 2, the best-response functions under free trade are upward-sloping (reflecting strategic complementarity) up to their point of intersection with the $45^{\circ}$ line, and downward sloping (reflecting strategic substitutability) thereafter. When the two contending countries hold identical endowments of secure resources, they face identical marginal benefit and marginal cost functions for guns, thereby yielding the symmetric equilibrium, point $A$ in Figure 2 where $G_{F}^{i *}=G_{F}^{j *}=G_{F}^{*}$ and since $\pi=\widetilde{p}_{A}^{*}, G_{F}^{*}=\widetilde{G}_{A}^{*} \cdot{ }^{20}$

What about when secure endowments are unevenly distributed across the two countries?

\footnotetext{
${ }^{18}$ As in the case of autarky, countries will not use their entire labor endowments in the production of guns, provided that both factors are essential in the production of consumption goods.

${ }^{19}$ The proofs of existence and uniqueness of equilibrium are similar to those presented for the case of autarky (see the Appendix). To be sure, existence and uniqueness of equilibrium arise under less restrictive conditions than (i) and (ii). However, relaxing these two conditions only complicates the analysis without altering the key insights of our comparison of conflict under autarky and free trade.

${ }^{20}$ As before, the point $(0,0)$ is not an equilibrium (see footnote 14 ).
} 
Provided that the distribution is such that free trade in consumption goods implies international factor price equalization ${ }^{21}$ and such that the production of guns does not exhaust either country's secure land resources, ${ }^{22}$ the contending states will continue to face identical marginal benefit and marginal cost functions for guns, thus again yielding the symmetric Nash equilibrium: $G_{F}^{i *}=\widetilde{G}_{A}^{*}$ for $i=1,2$ when $\pi=\widetilde{p}_{A}^{*}$. We label this set of distributions the "arms equalization set" $(A E S)$. Under free trade given $\pi=\widetilde{p}_{A}^{*}$, redistributions of secure endowments across the two contending countries within the AES have no effect on their arming. ${ }^{23}$ We note that, while the sets $\mathcal{S}^{0}, \mathcal{S}^{1}$, and $\mathcal{S}^{2}$ are defined under autarky and thus are independent of the world price, the $A E S$ subsets of $\mathcal{S}^{0}, \mathcal{S}^{1}$, and $\mathcal{S}^{2}$ for which free trade leads to arms equalization are not: as $\pi$ moves away from $\widetilde{p}_{A}^{*}$, these subsets shrink.

We now turn to explore the implications of changes in international prices for arming. To proceed, note that, given the allocation of secure resources, there exists a range of prices $\left(\underline{\pi}^{i}, \bar{\pi}^{i}\right)$ for each country $i$ that ensures diversification in the production of consumption goods for that country. Then, for world prices $\pi \in(\underline{\pi}, \bar{\pi})$, where $\underline{\pi}=\max \left\{\underline{\pi}^{1}, \underline{\pi}^{2}\right\}$ and $\bar{\pi}=\min \left\{\bar{\pi}^{1}, \bar{\pi}^{2}\right\}$, production is diversified in both countries. By contrast, for world prices $\pi \notin(\underline{\underline{\pi}}, \overline{\bar{\pi}})$, where $\underline{\underline{\pi}} \equiv \min \left\{\underline{\pi}^{1}, \underline{\pi}^{2}\right\} \leq \underline{\pi}$ and $\overline{\bar{\pi}} \equiv \max \left\{\bar{\pi}^{1}, \bar{\pi}^{2}\right\} \geq \bar{\pi}$, both countries specialize in production. ${ }^{24}$ Using these definitions, we have the following:

Lemma 2 (Arming and International Prices) Assume that secure land endowments are not exhausted in the production of guns. Then,

(a) equilibrium guns are increasing in the world price of the land-intensive good for world prices $\pi \in(\underline{\pi}, \bar{\pi})$ (i.e., $d G_{F}^{i *} / d \pi \gtrless 0 \forall \pi \in(\underline{\pi}, \bar{\pi})$ if $k_{2}^{i} \gtrless k_{1}^{i}$, for $\left.i=1,2\right)$; and,

(b) equilibrium guns are invariant to price changes for all world prices $\pi \notin(\underline{\underline{\pi}}, \overline{\bar{\pi}})$ (i.e., $\left.d G_{F}^{i *} / d \pi=0, \forall \pi \notin(\underline{\underline{\pi}}, \overline{\bar{\pi}})\right)$.

\footnotetext{
${ }^{21}$ The conditions for international factor price equalization include, as in the standard HOS trade model, constant returns to scale in production, the absence of factor intensity reversals, identical technologies across countries, diversification in production, absence of market failures or distortions, no trade barriers, and the existence of at least as many productive factors in the tradable goods sectors as there are traded goods (Samuelson, 1949). For distributions of secure resources where these conditions are not satisfied, at least one country will specialize in the production of one consumption good. Such specialization precludes the possibility of international factor price equalization and renders a country's marginal cost of producing guns independent of the world price, but increasing in its arms.

${ }^{22}$ Even where one country's secure land constraint binds in the production of guns, free trade in consumption goods can nonetheless lead to factor price equalization. Once the disputed land is divided, both countries diversify in their production of the two goods. However, due to the binding resource constraint, the marginal benefit of producing more arms is not equalized across countries. Accordingly, free trade does not lead to arms equalization in this case, and more generally factor price equalization alone need not imply arms equalization.

${ }^{23}$ These findings would remain unchanged assuming alternative specifications for the conflict technology as described earlier in footnote 15 .

${ }^{24}$ Of course, for identical adversaries, $\underline{\underline{\pi}}=\underline{\pi}$ and $\overline{\bar{\pi}}=\bar{\pi}$. But, for adversaries having different secure factor endowments, there also exist price ranges for which one country's gun choices depend on prices while the other country's do not-namely, $(\underline{\underline{\pi}}, \underline{\pi})$ and $(\bar{\pi}, \overline{\bar{\pi}})$. However, these complications are not relevant for our arguments.
} 
The proof of this lemma is fairly straightforward. Suppose once again that good 2 is land intensive $\left(k_{2}^{i}>k_{1}^{i}\right)$. If the conditions specified in part (a) are satisfied, factor prices and arms are equalized across countries. Now, let the world price of good $2(\pi)$ rise. While this price change has no effect on either country's marginal benefit of arming $\left(M B^{i}\right)$, by the Stolper-Samuelson theorem the wage-rental ratio in each contending country will fall; and, as previously discussed, this adjustment in factor prices will cause each country $i$ 's marginal cost of arming $\left(M C_{F}^{i}\right)$ to fall, thereby inducing both to arm more heavily. (Analogous reasoning establishes that, when good 1 is land intensive $\left(k_{1}^{i}>k_{2}^{i}\right)$, an increase in $\pi \in(\underline{\pi}, \bar{\pi})$ will induce less arming.) Turning to part (b), note that, from equations (2)-(5), price changes outside the relevant range for country $i, \pi \notin\left(\underline{\pi}^{i}, \bar{\pi}^{i}\right)$, force all factor prices to rise proportionately in that country and thus have no effect on the marginal cost of arming. Part (b), then, follows from the condition imposed implying both countries specialize in production. But, for our purposes, the important point is that changes in world prices can induce changes in the two contending countries' arming choices.

Although the qualitative nature of the link between the relative world price of good 2 and the countries' arming choices in the free-trade equilibrium depends on technology (and in particular the relative factor intensities of the production of goods 1 and 2), for simplicity and clarity we henceforth maintain the assumption that good 2 is land intensivei.e., $k_{2}^{i}>k_{1}^{i}$. Unless otherwise noted, the results that follow remain intact regardless of the ranking of factor intensities.

\section{Trade Patterns and Trade Volumes}

Naturally, the direction of a country's trade flows depends on the world price. To explore this issue, define $\pi_{A}^{i}$ as the level of the world price that eliminates country $i$ 's trade: $M_{F}^{i *}(\pi) \lessgtr 0$ if $\pi \gtrless \pi_{A}^{i} \cdot{ }^{25}$ In what follows, we contribute two ideas to the literature. First, we illustrate that international contestation of resources alters a country's trade-eliminating price relative to the case of no conflict and can thus affect its observed comparative advantage. Second, we show that such conflict can drive a wedge between a country's autarkic price and trade-eliminating price under free trade such that a simple comparison of international and autarkic prices need not provide an accurate prediction of trade patterns in

\footnotetext{
${ }^{25}$ As in the neoclassical version of this setting with no insecurity, the negative influence of the world price $\pi$ on each country's excess demand $M_{F}^{i *}(\pi)$ follows from what is effectively a condition for stability of general equilibrium under free trade. However, when there is insecurity, one has to account for the indirect influence of a change in $\pi$ on the country's residual land-labor ratio $k_{X}^{i}$, through its effect on arming by both countries. As such, the presence of insecurity makes the condition for stability slightly more complicated. Interestingly, this condition is identical to a sufficient condition for uniqueness of the Nash equilibrium under autarky (see equation (A.17) and the surrounding discussion in the Appendix). Intuitively, this makes sense, since prices under autarky change to clear domestic markets and policymakers take that effect into account when choosing their guns.
} 
contending countries.

To flesh out the effects of conflict on a contending country's comparative advantage, consider the case of identical adversaries. Let $p_{A}(G)$ denote each country's autarkic price as it depends on the common quantity of guns, $G$. When evaluated at the equilibrium level of arming under autarky $\left(G_{A}^{i *}=\widetilde{G}_{A}^{*}\right), p_{A}(G)=\widetilde{p}_{A}^{*}$ holds. Furthermore, when $\pi=\widetilde{p}_{A}^{*}$, the equilibrium under free trade coincides precisely with the equilibrium under autarky. That is to say, the world price that eliminates a contending country's trade flows equals the equilibrium price that obtains under autarky (i.e., $\pi_{A}^{i}=\widetilde{p}_{A}^{*}$ ). Therefore, under conflict and trade, both adversaries will export the land-intensive good $(j=2)$ if $\pi>\widetilde{p}_{A}^{*}$ and will import it if $\pi<\widetilde{p}_{A}^{*}$. In the hypothetical case of no arming, from equation (1), each adversary continues to receive $\frac{1}{2}$ of the contested resource $K_{0}$, but the autarkic price coincides with the price $p_{A}^{n}=p_{A}(0)$. (The superscript " $n$ " stands for "no conflict" or "Nirvana.") Thus, in the absence of conflict, the representative country would export the land-intensive good if $\pi>p_{A}^{n}$ and would import it if $\pi<p_{A}^{n}$.

The effect of conflict on the identical countries' trade patterns ultimately stems from the alternative use of the countries' secure resources its presence implies - namely, the production of guns. The effect, which works through the countries' residual factor endowments, depends on land-labor ratio in the production of guns $k_{G}^{i}(\omega)=\psi_{r}^{i} / \psi_{w}^{i}$ relative to land-labor ratio $k_{i}=\frac{K^{i}+\phi^{i} K_{0}}{L^{i}}$, where $\phi^{i}(G, G)=\frac{1}{2}$. In particular, when guns production is sufficiently labor intensive (i.e., $k_{G}^{i}(\omega)<k^{i}$ ), an exogenous equi-proportionate increase in guns by the two countries absorbs relatively more labor, implying that less is available for the production of the two traded goods: the two countries' residual land-labor ratios, therefore, rise. Under the maintained assumption that good 2 is produced intensively with land, the equilibrium price under autarky for each country, $p_{A}(G)$, is decreasing in $G$. Therefore, we have $p_{A}^{n}=p_{A}(0)>p_{A}\left(\widetilde{G}_{A}^{*}\right)=\widetilde{p}_{A}^{*}$. Now suppose $\pi \in\left(\widetilde{p}_{A}^{*}, p_{A}^{n}\right)$. Obviously, since $\pi<p_{A}^{n}$, under no conflict both countries would import good 2. But, since $\pi>\widetilde{p}_{A}^{*}$ at the same time, under conflict each country exports good 2. Alternatively, if guns production is sufficiently land intensive (i.e., $k_{G}^{i}(\omega)>k^{i}$ ), then $p_{A}(G)$ is increasing in $G$ and as a result $p_{A}^{n}<\widetilde{p}_{A}^{*}$. Thus, if $\pi \in\left(p_{A}^{n}, \widetilde{p}_{A}^{*}\right)$, then each country exports the land-intensive good $(j=2)$ in the hypothetical case of no conflict, and imports it under conflict. Thus, we have

Proposition 1 (Trade Patterns with Identical Adversaries) Conflict over land reverses the contending countries' comparative advantage for $\pi \in\left(\widetilde{p}_{A}^{*}, p_{A}^{n}\right)$ if $k^{i}>k_{G}^{i}(\omega)$, or for $\pi \in\left(p_{A}^{n}, \widetilde{p}_{A}^{*}\right)$ if $k^{i}<k_{G}^{i}(\omega)$, as compared with what would be observed in the hypothetical case of no conflict.

Although the nature of the distortion of conflict on trade patterns of identical countries also depends on the relative ranking of factor intensities in industries $j=1,2$, the result that 
such a distortion can emerge does not. ${ }^{26}$

Our analysis suggests further that viewing international conflict over productive resources as a type of trade cost that necessarily reduces the size of a contending country's trade flows might be inappropriate. If, for example, $\pi=p_{A}^{n}$, then in the absence of conflict the countries would not engage in trade. But, as we have just seen, in the presence of conflict, the contending countries will be net exporters (importers) of the land-intensive $\operatorname{good}$ if $k^{i}>k_{G}^{i}(\omega)\left(k^{i}<k_{G}^{i}(\omega)\right)$. Of course, if $\pi=\widetilde{p}_{A}^{*}$, then the two countries in conflict would not engage in trade, whereas in the hypothetical case of no conflict the two countries would engage in trade. Thus, depending on the world price, international conflict can either expand or shrink trade volumes. ${ }^{27}$ In any case, one can show more generally that conflict, through its absorption of secure resources in the production of guns, imparts a positive bias, relative to the hypothetical case of no conflict, on each country's tendency to export (import) the good produced intensively with land if guns production is sufficiently labor (land) intensive. ${ }^{28}$

Moving on to the second main point of this section, neoclassical trade theory tells us that a country's trade pattern can be identified by comparing the world price to its autarkic price. However, in the world of insecure property and international conflict, a country's trade-eliminating price under free trade need not coincide with its autarkic price, particularly when there are differences in secure factor ownership across the two contending countries. The reason is simply that the distortion of conflict, resulting from the absorption of secure resources in the production of guns, is trade-regime dependent. As such, an unqualified application of the standard logic normally used in trade theory can lead to erroneous inferences about trade patterns.

Now, it should be clear from our earlier discussion in Section 3.2 that, when the (uneven) distribution of secure resources lies in the AES subset of $\mathcal{S}^{0}$, the trade-eliminating price for each country does coincide with the autarkic price: $\pi_{A}^{i}=\widetilde{p}_{A}^{*}$. That is to say, a shift to free trade with $\pi=\widetilde{p}_{A}^{*}$ induces no changes in the contenders' factor prices and thus no change in their arming. As such, the standard logic does apply: if $\pi \gtrless \widetilde{p}_{A}^{*}$, then $M_{F}^{i *}(\pi) \lessgtr 0$. Matters differ, however, when the distribution falls in the AES subset of $\mathcal{S}^{i}, i=1$ or 2 . For in this case, the introduction of free trade, through its impact on factor prices and thus arming incentives, alters the countries' residual factor endowments and therefore their excess demand functions.

\footnotetext{
${ }^{26}$ This result is reminiscent of Brander and Taylor's (1997b) finding that, over time, the depletion of a common-pool resource in a country with ill-defined property rights can reverse its comparative advantage. In our setting, residual factor endowments (and thus comparative advantage) can change simply due to the dissipation of secure resources in conflict.

${ }^{27}$ The relationship between the volume of trade and conflict has been addressed empirically in the political science literature (e.g., Barbieri, 2002), finding support for the idea that conflict might stimulate trade.

${ }^{28}$ See Proposition A.1 and its proof in the Appendix.
} 
To gain some intuition here, suppose that the world price equals country 2's autarkic price $\left(\pi=p_{A}^{2 *}\right)$ and consider a distribution of secure resources in the AES subset of $\mathcal{S}^{1}$, where country 1 is relatively more aggressive under autarky, as illustrated by point $A^{\prime}$ in Fig. 2. From (9), the introduction of free trade would give country 2 no incentive to adjust its guns choice as long as country 1 maintains is guns choice, $G^{1}=G_{A}^{1 *}$. However, note that, by Lemma $1(\mathrm{~b}), p_{A}^{2 *}<p_{A}^{1 *}$ holds. Thus, a shift to free trade, with the lower price $\pi=p_{A}^{2 *}$ and thus a higher wage-rental ratio, induces country 1 to decrease its guns $\left(G^{1}\right)$; and, given the negative influence of $G^{1}$ on $B_{F}^{2}\left(G^{1}\right)$ for $G^{2}<G^{1}$, this adjustment in country 1's guns choice, in turn, induces country 2 to increase its guns until the free trade equilibrium, where arms are equalized, is reached. With $G^{2}$ rising and $G^{1}$ falling, country 2's residual land-labor ratio, $k_{X}^{2}$, necessarily increases. ${ }^{29}$ Then, from the Rybczynski theorem, country 2's excess supply of good 2, when evaluated at the autarkic price, $p_{A}^{2 *}$, is strictly positive. As such, the world price that eliminates country 2 's trade, $\pi_{A}^{2}$, must be below the country's autarkic price, $p_{A}^{2 *} \cdot 30$ Similar reasoning establishes that $\pi_{A}^{1} \neq p_{A}^{1 *}$ almost always. In particular, a move to free trade with $\pi=p_{A}^{1 *}>p_{A}^{2 *}$ induces both countries to increase their arming and these adjustments have offsetting effects on country 1's residual land-labor ratio $\left(k_{X}^{1}\right)$. It would be only by coincidence that $\pi_{A}^{1}=p_{A}^{1 *}$. It is possible that $\pi_{A}^{1}<p_{A}^{1 *}$, but in most circumstances $\pi_{A}^{1}>p_{A}^{1 *} \cdot{ }^{31}$

The following proposition summarizes these results and takes them a step further:

Proposition 2 (Trade Patterns with Nonidentical Adversaries) For uneven secure factor endowments in the AES subset of $\mathcal{S}^{0}$, we have $\pi_{A}^{i}=\widetilde{p}_{A}^{*}$, as in the neoclassical trade theory. $B u t$, for distributions in the AES subset of $\mathcal{S}^{i}$ assuming world prices in the neighborhoods of $p_{A}^{i *}$ and $p_{A}^{j *}$, we have $\pi_{A}^{i} \neq p_{A}^{i *}$ almost always, and $\pi_{A}^{j}<p_{A}^{j *}$ always, such that comparing the international price to a contending country's autarkic price need not give an accurate prediction of that country's trade pattern.

The key point to take from Proposition 2 is that there can be some divergence between a country's autarkic price and its trade-eliminating price under free trade, so as to alter the informational content of the difference between the world price and the autarkic price. Returning to our example, for $\pi \in\left(\pi_{A}^{2}, p_{A}^{2 *}\right)$, the country that is less aggressive in the autarkic equilibrium $(i=2)$ exports good 2 under free trade, whereas neoclassical theory predicts that it imports the good. Clearly, if equilibrium arming were independent of the trade regime, the trade eliminating price and the autarkic price would be the same. But,

\footnotetext{
${ }^{29}$ See Lemma A.7(a) for a formal proof.

${ }^{30}$ Assuming instead that $k_{1}^{i}>k_{2}^{i}$ implies a reversal in the ranking of $\pi_{A}^{2}$ and $p_{A}^{2 *}$.

${ }^{31}$ As revealed by equation (A.25) in the Appendix, $k_{X}^{1}$ tends to fall on net as both countries increase their arming, provided that country 1's cost share of labor in the production of guns $\left(\theta_{L G}^{1}=w^{1} \psi_{w}^{1} / \psi^{1}\right)$ is not too large relative to country 1's labor share in total net income $\left(s_{L}^{1}=w^{1} L_{X}^{1} / R^{1}\right)$; a sufficient (but not necessary) condition is that $\theta_{L G}^{1}<2 s_{L}^{1}$ (see the proof to Lemma A.7). Note that if $k_{1}^{i}>k_{2}^{i}$, then in most circumstances $\pi_{A}^{1}<p_{A}^{1 *}$.
} 
for an uneven distribution of secure endowments across the two countries in the AES subset of $\mathcal{S}^{i}$, the trade regime does influence arming that influences each country's excess demand function and thus drives a wedge between these two prices. Accordingly, the direction of trade flows is not determined by how the international price differs from the country's autarkic price, $p_{A}^{i *}$, but rather how it differs from its trade-eliminating price, $\pi_{A}^{i}$.

\section{Welfare Comparison of Trade Regimes}

In this section, we show that a move from autarky to free trade need not be welfare improving. The analysis not only clarifies how international conflict generates a trade-regime dependent distortion (Bhagwati, 1971), but also sheds light on the conditions under which free trade intensifies this distortion.

To start, consider the welfare decomposition in (8) where $p^{i}=\pi$. With the envelope theorem, it implies

$$
\frac{d V_{F}^{i *}}{d \pi}=\mu(\pi)\left[-M_{F}^{i *}+r(\pi) K_{0} \phi_{G^{j}}^{i} \frac{d G_{F}^{j *}(\pi)}{d \pi}\right], \quad \text { for } i=1,2 \text { and } j \neq i
$$

The first term inside the brackets, weighted by the marginal utility of income $(\mu(\pi))$, captures the direct welfare effect of a price change, and its sign is determined by the country's trade pattern. It is positive for net exporters of the non-numeraire good $\left(M_{F}^{i *}<0\right)$, and negative for net importers $\left(M_{F}^{i *}>0\right)$. The second term (again weighted by $\mu(\pi)$ ) captures the strategic welfare effect of a price change. Specifically, by Lemma 2(a) under the maintained assumption that $k_{2}^{i}>k_{1}^{i}$, when production is diversified an increase in $\pi$ induces the opponent to increase its guns $\left(G^{j}\right)$, which (given $G^{i}$ ) reduces the share of the disputed land secured by country $i$. Therefore, this indirect effect on country $i$ 's welfare is negative. But, by Lemma 2(b), an increase in $\pi$ above $\overline{\bar{\pi}}$ or a decrease in $\pi$ below $\underline{\underline{\pi}}$ leaves arming unchanged, and so the strategic effect vanishes. The next lemma builds on these ideas:

Lemma 3 (International Prices and Welfare) A contending country $i$ 's welfare is

(a) decreasing in the world price of the good that employs intensively the contested resource (land), in the neighborhood of $\pi=\pi_{A}^{i}$ (i.e., $\left.d V_{F}^{i *}\left(\pi_{A}^{i}\right) / d \pi<0\right)$;

(b) increasing in the world price of the good that employs intensively the contested resource (land) for $\pi>\overline{\bar{\pi}}$; and,

(c) minimized at a world price, $\pi=\pi_{\min }^{i}\left(>\pi_{A}^{i}\right)$.

Part (a) shows that an improvement in a contending country's terms of trade is necessarily "immiserizing" if the country exports the land-intensive product and provided that $\pi$ does not differ considerably from its trade eliminating price, $\pi_{A}^{i}$. Specifically, in the neighborhood 
of $\pi_{A}^{i}$, the direct, positive effect of a terms of trade improvement on country $i$ 's income (the first term in (11)) is swamped by the loss in income due to its opponent's increased aggressiveness (the second term in (11)). However, part (b) indicates that, when the world price becomes sufficiently large to induce specialization in production by both countries $\left(\pi>\overline{\bar{\pi}}\right.$ such that $\left.\partial G_{F}^{i} / \partial \pi=0\right)$, this latter effect vanishes, leaving only the direct (positive) welfare effect of the terms of trade improvement. Finally, part (c) indicates that a country's welfare is minimized at some price, $\pi_{\min }^{i}>\pi_{A}^{i}$, where the beneficial, direct effect of a terms of trade improvement equals the adverse strategic effect that results from increased arms production by the rival country. ${ }^{32}$

Thus, there exists a range of world prices, $\pi \in\left(\pi_{A}^{i}, \pi_{\text {min }}^{i}\right)$, for which international conflict over resources can expose contending countries with an apparent comparative advantage in the contested-resource-intensive products to the "resource curse" problem. Others have attributed the problem to domestic rent-seeking (e.g., Torvik, 2002; Mehlum et al., 2006), redistributive politics (e.g., Robinson et al., 2005), and domestic conflict (e.g., Garfinkel et al., 2008; Dal Bo and Dal Bo, 2011). But, our finding suggests that the absence or ineffectiveness of international institutions aimed at managing international conflict has a bearing on this problem as well.

Although country size is inconsequential in the determination of the quantity of guns that adversaries produce under free trade for secure factor endowments in the AES, country size does matter for the determination of the range of international prices for which the resource curse problem arises. Consider, for example, an uneven distribution of secure resources in the $A E S$ subset of $\mathcal{S}^{0}$, where country 1 holds larger endowments of both secure labor and secure land than country 2 and where initially $\pi=\pi_{A}^{i}=\widetilde{p}_{A}^{*}$. The strategic welfare effect of an increase in $\pi$ above $\widetilde{p}_{A}^{*}$ (the second term in (11)) will not differ across adversaries. However, the marginal benefit from such a price increase (the first term in (11)) will differ. Since, by construction, country 1 is larger than country 2, country 1 will be relatively more involved in trade than its rival (i.e., $-M_{F}^{1 *}>-M_{F}^{2 *}>0$ ) for $\pi>\widetilde{p}_{A}^{*}$, which implies $\pi_{\text {min }}^{1}<\pi_{\text {min }}^{2}$. Accordingly, for uneven factor distributions in $\mathcal{S}^{0}$, the relatively smaller adversary ( $i=2$ in our example) will experience the resource curse problem over a larger range of international prices.

To proceed with our comparison of welfare across the two trade regimes, we consider two possibilities: (i) when adversaries are identical, which unveils the gist of the argument and the circumstances under which autarky dominates trade; and, (ii) when adversaries have different endowment profiles, which sheds some light on the conditions under which national preferences over trade regimes can diverge.

Whether secure resources are identically distributed across the two countries or not,

\footnotetext{
${ }^{32}$ The proof of this lemma, presented in the Appendix, verifies that analogous results obtain when $k_{1}^{i}>k_{2}^{i}$.
} 
the welfare decomposition in equation (11) suggests that there are two forces at play in determining the relative appeal of free trade, both of which depend on the world price: (i) the gains from trade and (ii) the costs of insecurity. Starting with the gains from trade as predicted by the neoclassical theory, a country's welfare given guns increases with the deviation of the world price from its autarky level $p_{A}^{i *}{ }^{33}$ Given our focus here on identical adversaries, the gains are equal to zero when the world price $\pi$ equals $\widetilde{p}_{A}^{*}$, and increasing as $\pi$ increases or decreases from that price. If the countries' incentive to arm were independent of the world price, then as the neoclassical theory predicts a shift to free trade with $\pi \neq \widetilde{p}_{A}^{*}$ would unambiguously be welfare improving.

However, as we have already seen, the incentive to arm for each country does change with the world price, and thus so do the costs of insecurity. Let $G^{*}(\pi)$ denote the equilibrium quantity of guns under free trade, as implicitly defined by (9), when the two adversaries are identical. By Lemma 2(a) under the maintained assumption that good 2 is produced intensively with land, $G^{*}(\pi)$ is increasing in $\pi$ for $\pi \in(\underline{\pi}, \bar{\pi})$. Since equi-proportionate increases in arms do not alter the division of the contested land but do increase the resource costs of insecurity, these costs are strictly increasing in $\pi$ over that range. Thus, for $\pi>\widetilde{p}_{A}^{*}$, a discrete move from autarky to free trade intensifies the conflict between the two countries, inducing more arming, and thus larger insecurity costs. By contrast, for $\pi<\widetilde{p}_{A}^{*}$, a move to free trade from autarky weakens the conflict, inducing less arming and thus smaller insecurity costs. ${ }^{34}$

Now, when $\pi=\widetilde{p}_{A}^{*}, G(\pi)=\widetilde{G}_{A}^{*}=\widetilde{G}_{F}^{*}>0$; thus, the security costs are strictly positive, but the same across the two trade regimes. Furthermore, since $\widetilde{p}_{A}^{*}$ coincides with the tradeeliminating price, the gains from trade are equal to zero when $\pi=\widetilde{p}_{A}^{*}$. As such, welfare is the same across the two trade regimes: $V_{F}^{*}\left(\widetilde{p}_{A}^{*}\right)=\widetilde{V}_{A}^{*}$. The next proposition goes further to show how the familiar gains from trade and the costs of insecurity combined determine the relative appeal of free trade for other world prices:

Proposition 3 (Relative Appeal of Free Trade with Identical Adversaries) If free trade in consumption goods induces adversaries with identical endowment profiles to

(a) import the land-intensive good, there will be less arming under free trade than under autarky, and free trade will Pareto dominate autarky;

(b) export the land-intensive good, then the adversaries will arm more heavily under free

\footnotetext{
${ }^{33}$ See Lemma A.3(d)).

${ }^{34}$ Note the difference between this result and that of Hirshleifer (1991), who explored the implications of conflict over output, identifying market integration with the degree of complementarity between the inputs in useful production. Specifically, he observed that the diversion of resources into arms falls with the degree of market integration, although the size of this effect is small. Our approach suggests that, when conflict is over resources and market integration takes the form of a move from more protected (autarky) to less protected (free trade) trade regimes, the severity of conflict (measured by the level of arming) can rise or fall depending on, among other things, technology, the degree of resource insecurity and international prices.
} 
trade than under autarky, and free trade will be Pareto dominated by autarky for a certain range of international prices close enough to the autarkic price.

For world prices $\pi<\widetilde{p}_{A}^{*}$ where countries import the land-intensive product, the gains from trade reinforce the negative effect of trade on equilibrium costs of insecurity, such that free trade is Pareto superior to autarky: $V_{F}^{*}(\pi)>\widetilde{V}_{A}^{*}$. For $\pi>\widetilde{p}_{A}^{*}$ where the countries export the land-intensive product, the gains from trade are positive, but the costs of insecurity are larger. And, we know from Lemma 3(a), that the higher costs of insecurity swamp the gains from trade in the neighborhood of $\pi=\widetilde{p}_{A}^{*}$. Furthermore, by the continuity of $V_{F}^{*}(\pi)$ in $\pi$ and Lemma 3, there exists a world price $\pi^{\prime}$ that satisfies $V_{F}^{*}\left(\pi^{\prime}\right)=\widetilde{V}_{A}^{*}$, where the maintained assumption that good 2 is land intensive implies $\pi^{\prime}>\pi_{\min }>\tilde{p}_{A}^{*}$. Thus, for international prices $\pi \in\left(\widetilde{p}_{A}^{*}, \pi^{\prime}\right)$ such that each contestant exports the contested-resourceintensive product, autarky will Pareto dominate free trade: $\widetilde{V}_{A}^{*}>V_{F}^{*}(\pi)$.

What about adversaries with different endowment profiles? Arbitrary factor distributions in $\mathcal{S}^{i}$ can complicate the welfare ranking of trade regimes for at least two reasons. First, because adversaries begin to specialize in production at different international prices, it becomes necessary to investigate arming incentives outside the AES for one country initially and eventually for both. Second, the endogeneity of trade patterns together with the fact that $V_{F}^{i *} \neq V_{A}^{i *}$ at $\pi=p_{A}^{i *}$ for arbitrary distributions in $\mathcal{S}^{i}$ make it difficult to identify workable benchmarks for comparison purposes. Still, as the next proposition illustrates, there exist two noteworthy asymmetries that yield tractable comparisons.

\section{Proposition 4 (Relative Appeal of Free Trade with Nonidentical Adversaries)}

(a) For any uneven factor distribution in the AES subset of $\mathcal{S}^{0}$, there exists a range of international prices that render autarky Pareto superior to free trade.

(b) If $\pi=\widetilde{p}_{A}^{*}$, there exist subsets $\mathcal{D}^{i} \subseteq \mathcal{S}^{i}$ of factor distributions adjacent to the AES subset of $\mathcal{S}^{0}$ such that one country prefers autarky over free trade while its adversary does not.

Part (a) extends Proposition 3 to uneven distributions in the AES subset of $\mathcal{S}^{0}$. Part (b) clarifies how the countries' preferences over trade regimes might differ when more general factor endowment asymmetries are considered. As shown in the proof (presented in the Appendix), the divergence in preferences arises from the presence of a strategic effect when redistributing resources under autarky (Lemma A.6), and the absence of such a strategic effect under free trade. It is possible to show further, for world prices other than $\widetilde{p}_{A}^{*}$, that at least one country prefers autarky over free trade, and this preference could hold even for a country that imports the good produced intensively with the contested resource. ${ }^{35}$

\footnotetext{
${ }^{35}$ See Proposition A.2 and its proof in the Appendix.
} 


\section{Strategic Considerations in the Choice of Trade Regimes: A Prisoners' Dilemma Outcome}

Our result above that autarky Pareto dominates free trade for a certain range of world prices naturally raises the question of whether the countries would choose autarky or free trade when such prices prevail. In exploring this issue, we focus on the case where the two countries are identical and choose their trade regimes simultaneously and prior to the first stage when they make their guns choices. Each country $i$ 's choice induces a particular relative price of good 2 for that country, given the trade regime chosen by the opponent $j$ and the implied relative price it faces, $p^{j}$. So, for example, a choice of free trade by country $i$ implies that it faces a relative price of $\pi$, whereas a choice of autarky implies a relative price of $p_{A}^{i}\left(p^{j}\right)$. In what follows, then, we consider the possibility that the two countries face different relative prices, and let $V^{i}\left(p^{i}, p^{j}\right)$ for $i=1,2$ and $j \neq i$ denote the corresponding payoff functions.

The implications of choosing one regime over the other for a country's payoffs can be decomposed into a terms of trade effect and a strategic effect according to equation (8) with the envelope condition. A choice of free trade over autarky generally implies a nonnegative terms of trade effect (i.e., the familiar gains from trade). The strategic effect works through the influence of a shift in trade regimes by country $i$ (e.g., moving from $B_{A}^{i}\left(G^{j}\right)$ to $\left.B_{F}^{i}\left(G^{j} ; \pi\right)\right)$ on opponent $j$ 's guns choice: a positive response by country $j$ gives a negative strategic effect on country $i$ 's payoff, and a negative response gives a positive effect. $^{36}$ To fix ideas, we maintain the assumption that good 2 is produced intensively with the contested resource, and consider world prices that fall within the range implying $V_{F}^{*}(\pi, \pi)<\widetilde{V}_{A}^{*}=V_{F}\left(\pi^{\prime}, \pi^{\prime}\right)$-namely, $\pi \in\left(\widetilde{p}_{A}^{*}, \pi^{\prime}\right) .{ }^{37}$

Focusing on the incentives for country 1, suppose for now that country 2 does not engage in trade, and denote its market-clearing price by $p_{A}^{2}$. Then, country 1 has the choice of trading freely at $\pi$ or remaining under autarky and so facing a relative price of $p_{A}^{1}\left(p_{A}^{2}\right)=\widetilde{p}_{A}^{*}$. Thus, the relevant comparison of payoffs here is between $V_{F}^{1}\left(\pi, p_{A}^{2}(\pi)\right)$ and $\widetilde{V}_{A}^{*}$. Notice that at $\pi=\widetilde{p}_{A}^{*}$, the two payoffs are equal.

Now consider a small departure from the symmetric autarkic regime: $\pi=\widetilde{p}_{A}^{*}+\varepsilon$ for very small $\varepsilon>0$. Since the increase in the world price has no effect on outcomes when both countries remain in autarky and the terms of trade effect associated with $V_{F}^{1}\left(\pi, p_{A}^{2}(\pi)\right)$

\footnotetext{
${ }^{36}$ If instead each country were to choose its trade regime after having already produced its guns, then only the terms of trade effect would matter, and as such both countries would necessarily choose free trade at any world price. Of course, each country would anticipate this choice and arm accordingly in the first stage, such that the welfare comparisons made in the previous section would continue to hold.

${ }^{37}$ Recall that $\pi^{\prime}$ was defined in the previous section as the world price, greater than $\pi_{\min }>\widetilde{p}_{A}^{*}$, such that $V_{F}^{*}\left(\pi^{\prime}, \pi^{\prime}\right)=\widetilde{V}_{A}^{*}$ holds. Note that it is possible to extend the analysis to consider world prices outside the range $\left(\widetilde{p}_{A}^{*}, \pi^{\prime}\right)$. But, our interest here concerns the outcomes of the non-cooperative game of regime choices when autarky Pareto dominates free trade.
} 
vanishes in the neighborhood of $\pi=\widetilde{p}_{A}^{*}$, the difference in payoffs for country 1 in choosing between the two regimes involves only the strategic effect that arises when country 1 chooses free trade. In particular, the increase in $\pi$ induces country 1 to produce more guns given the guns chosen by country 2 (a clockwise rotation of $B_{F}^{1}\left(G^{2} ; \pi\right)$ in Fig. 2). The strategic complementarity of country 2's (stationary) best response function at the symmetric equilibrium under autarky (i.e., $\partial B_{A}^{2}\left(G^{1}\right) / \partial G^{1}>0$ in Fig. 2 at point $A$ ), in turn, implies that $V_{F}^{1}\left(\pi, p_{A}^{2}(\pi)\right)<\widetilde{V}_{A}^{*}$ for world prices just above the autarkic price, $\widetilde{p}_{A}^{*}$.

However, when $\pi$ is at the other end of the range of world prices under consideration, matters differ. In particular, note that $\pi^{\prime}>\widetilde{p}_{A}^{*}$ implies $p_{A}^{2}\left(\pi^{\prime}\right)<\pi^{\prime}{ }^{38}$ As such, country 2 's guns are lower than when both countries trade freely at $\pi^{\prime}$, and the implied strategic effect on country 1's payoff means $V_{F}^{1}\left(\pi^{\prime}, p_{A}^{2}\left(\pi^{\prime}\right)\right)>V_{F}^{1}\left(\pi^{\prime}, \pi^{\prime}\right)$. But, because $V_{F}^{1}\left(\pi^{\prime}, \pi^{\prime}\right)=$ $\widetilde{V}_{A}^{*}$ by the definition of $\pi^{\prime}$, we have $V_{F}^{1}\left(\pi^{\prime}, p_{A}^{2}\left(\pi^{\prime}\right)\right)>\widetilde{V}_{A}^{*}$. With these two results, the continuity of the payoff functions implies that there exists a critical price, $\pi^{\prime \prime}<\pi^{\prime}$, such that $V_{F}^{1}\left(\pi, p_{A}^{2}(\pi)\right)>\widetilde{V}_{A}^{*}$ for all $\pi \in\left(\pi^{\prime \prime}, \pi^{\prime}\right]$. In words, when country 2 chooses the autarkic regime, country 1 strictly prefers free trade over autarky for all prices in this range. In addition, assuming that $\pi^{\prime \prime}$ is unique, country 1 strictly prefers autarky over free trade for world prices $\pi \in\left(\widetilde{p}_{A}^{*}, \pi^{\prime \prime}\right)$ given country 2 chooses autarky.

Next, suppose country 2 trades freely at $\pi>\widetilde{p}_{A}^{*}$. In this case, country 1 effectively chooses between the price under autarky $p_{A}^{1}(\pi)$ with a payoff of $V_{A}^{1}\left(p_{A}^{1}(\pi), \pi\right)$ and the world price $\pi$ under free trade with a payoff of $V_{F}^{*}(\pi, \pi)$. Notice that at $\pi=\widetilde{p}_{A}^{*}$, which implies $p_{A}^{1}(\pi)=\widetilde{p}_{A}^{*}, V_{A}^{1}\left(p_{A}^{1}(\pi), \pi\right)=V_{F}^{*}(\pi, \pi)=\widetilde{V}_{A}^{*}$.

What happens as the world price rises above $\widetilde{p}_{A}^{*}$ ? When country 1 remains in autarky, only the adverse strategic effect comes into play. Provided country 2 continues to diversify in its production of the two consumption goods, this effect ensures that $V_{A}^{1}\left(p_{A}^{1}(\pi), \pi\right)$ is decreasing in the world price. As such, we know that $V_{A}^{1}\left(p_{A}^{1}(\pi), \pi\right)<\widetilde{V}_{A}^{*}$ for $\pi>\widetilde{p}_{A}^{*} \cdot{ }^{39}$ By contrast, when country 1 trades freely, increases in the world price generate both a positive terms of trade effect and a negative strategic effect on its payoff, $V_{F}^{*}(\pi, \pi)$, as described earlier in connection with Lemma 3. Nevertheless, as shown in the Appendix, we have the following:

Lemma $4 V_{A}^{i}\left(p_{A}^{i}(\pi), \pi\right)<V_{F}^{*}(\pi, \pi)$ for any $\pi \in\left(\widetilde{p}_{A}^{*}, \pi^{\prime}\right]$ and $i=1,2$.

Thus, despite the non-monotonicity of country 1's payoff under free trade in world prices,

\footnotetext{
${ }^{38}$ To verify this, suppose that $p_{A}^{2}\left(\pi^{\prime}\right)=\pi^{\prime}$, which implies that $G^{1}=G^{2}=G^{*}\left(\pi^{\prime}\right)$, with both countries exporting the land-intensive good, as in the free-trade regime when $\pi=\pi^{\prime}$. To wipe out that excess supply for country 2 , its autarkic price must be lower than $\pi^{\prime}$. This line of reasoning can be applied to show that $p_{A}^{1}(\pi)<\pi$ for all $\pi>\widetilde{p}_{A}^{*}$.

${ }^{39}$ Even if country 2 starts to specialize in production for some $\pi>\widetilde{p}_{A}^{*}$, which implies that the negative strategic effect on country 1's payoff disappears, this implication holds.
} 
we know that, for the range of prices under consideration, country 1 prefers free trade over autarky, given that country 2 trades freely with ROW.

Bringing this last result together with our earlier findings, while noting that the two countries are identical so that their incentives over trade regimes are symmetric, gives us the following:

Proposition 5 (Non-cooperative Choice of Trade Regimes by Identical Adversaries) For all $\pi \in\left(\widetilde{p}_{A}, \pi^{\prime}\right)$, free trade is a subgame perfect equilibrium of the extended game that is Pareto dominated by autarky. More precisely,

(a) when $\pi \in\left(\widetilde{p}_{A}^{*}, \pi^{\prime \prime}\right)$, there are two equilibria, one where both countries choose autarky and the other where both choose free trade; and

(b) when $\pi \in\left(\pi^{\prime \prime}, \pi^{\prime}\right)$, the outcome where both countries choose free trade is the unique, dominant-strategy equilibrium.

As part (b) of the proposition indicates, when the world price falls within the higher part of the range of prices under consideration (i.e., $\pi \in\left(\pi^{\prime \prime}, \pi^{\prime}\right)$ ), each country has an incentive to choose free trade over autarky, regardless of what regime the other country chooses. Although trade with higher world prices brings greater insecurity costs, each country views the gains from trade to be sufficiently large to swamp those costs regardless of the opponent's regime choice. Of course, as established in the previous section, when both countries choose free trade at any world price within this range, the equilibrium insecurity costs swamp the gains from trade for each country. Thus, the non-cooperative choice of trade regimes can result in a prisoners' dilemma. Part (a) of the proposition indicates that, even when the world price falls in the lower part of the range of prices under consideration (i.e., $\left.\pi \in\left(\widetilde{p}_{A}^{*}, \pi^{\prime}\right)\right)$, the same outcome where both countries choose free trade is possible, again despite the Pareto dominance of the outcome where both choose autarky.

\section{Concluding Remarks}

In the decades leading up to World War I, the proportion of world trade to world GDP had reached unprecedented magnitudes (O'Rourke and Williamson, 2000). Yet, international conflict ensued with much ferocity and despite expectations to the contrary. ${ }^{40}$ Similarly, the expansion of trade in the post World War II era has been spectacular. Still, while interstate conflict might have subsided over this latter period, insecurity and contention continue to flare up in many parts of the world. Whereas not all disputes can be considered to have material causes, there is no doubt that contestation of water resources, land, oil, diamonds

\footnotetext{
${ }^{40}$ The prediction before World War I, for example, that war was impossible or unthinkable-because Britain and Germany had become so economically interdependent that conflict was viewed as "commercial suicide" (Angell, 1933) — was flatly contradicted by experience.
} 
and other resources by different countries has at least some role to play in many international disputes and drives the military expenditures and security policies of the countries that are involved in such disputes.

The extent to which disputed resources or the goods they produce are tradable can have implications for the security policies that countries pursue and the costs those countries realize as a result. At the same time, the presence of such conflict can have implications for patterns of trade and welfare. We have explored these implications within the context of the neoclassical trade model augmented by a disputed resource that is costly to contest, considering two polar regimes: autarky and free trade. The key difference between these regimes for small countries is that prices are endogenously determined under autarky but not under free trade. As a consequence, arming incentives are trade-regime dependent.

The distortion in resource allocation caused by the presence of insecurity implies that a country's apparent comparative advantage can differ from its natural comparative advantage (absent insecurity). In addition, comparisons of autarkic prices to world prices could be inappropriate predictors of trade patterns. This latter finding suggests that empirical work aiming to relate trade volumes to fundamentals would be incomplete if it did not include insecurity and contestation of resources.

Furthermore, depending on the level of world prices, free trade in consumption goods might intensify arming incentives to generate additional security costs that swamp the traditional gains from trade and thus render autarky more desirable for one or both rival states. Our analysis extended to consider the non-cooperative choice of trade regimes by the two states does not indicate, however, that both states will necessarily choose autarky. To the contrary, we find that, for a range of world prices, each state has a dominant strategy to choose free trade even when the outcome is Pareto dominated by that which arises when both choose autarky. For other world prices that continue to imply the Pareto dominance of the outcome where both choose autarky, both symmetric outcomes are possible equilibria. One might conjecture that, for such world prices, the two countries could coordinate their regime choices on the better outcome - namely, autarky. But, notice that such coordination, even if it were possible, contrasts sharply with the sort of cooperation often advocated in policy circles. Indeed, our analysis suggests that pushing for free trade could be counterproductive, particularly when the fundamental source of the problem (i.e., resource insecurity) has not been resolved.

The basic model could be fruitfully extended in a number of ways. For example, the analysis could assign an active role to the rest of the world. Furthermore, the analysis could be generalized to situations where trade does not necessarily result in the equalization of factor prices, and thus give a meaningful role to the possibility of trade in arms. In addition, policy objectives could be specified to consider the role of politics. Last but not least, the 
analysis could be extended to include the case of countries with monopoly/monopsony power in world markets. Such an extension would allow one to explore not only the factor-price channel through which trade openness matters for the allocation of resources-when some of those resources are in dispute as emphasized here-but also the terms-of-trade channel which arises in the case of large countries. ${ }^{41}$

Ultimately, solving the problem of insecurity entails the design and development of commitment devices that can reduce, and possibly eliminate, the need to arm. Such commitment devices, however, are not easy to come by and, judging from particular historical instances, they take a long time to develop. Europe is a good example of this. After the experience of the two world wars, the original six members of the European Community slowly began to develop mechanisms of economic integration that were, in large part, institutions of conflict management. This twin process of economic integration and conflict resolution through bureaucratic and political struggle, instead of conflict in the battlefield, is ongoing and far from complete, even after a century of tribulations. Trade openness and, more generally, economic interdependence might help to ameliorate conflict, but it would be naive to think that promoting such interdependence could achieve this by itself.

\section{References}

Acemoglu, D., Golosov, M., Tsyvinski, A. and Yared, P., (2012) "A Dynamic Theory of Resource Wars," Quarterly Journal of Economics 121(1), 283-331.

Acemoglu, D., and Jensen, M.K., (2011) "Aggregate Comparative Statics," Manuscript, Massachusetts Institute of Technology.

Anbarci, N., Skaperdas, S., and Syropoulos, C., (2002) "Comparing Bargaining Solutions in the Shadow of Conflict: How Norms against Threats Can Have Real Effects," Journal of Economic Theory 106(1), 1-16.

Anderson, J.E. and Marcouiller, D., (2005) "Anarchy and Autarky: Endogenous Predation as a Barrier to Trade," International Economic Review 46(1), 189-213.

Anderton, C., Anderton, R., and Carter, J.R., (1999) "Economic Activity in the Shadow of Conflict," Economic Inquiry 37(1), 166-179.

Angell, N., (1933) The Great Illusion, (Second Edition), New York: G.P. Putnam's Sons.

\footnotetext{
${ }^{41}$ As noted in the introduction, we are currently exploring this additional channel in a Ricardian setting with a non-traded goods sector. Consistent with the results of the present paper, we find that trade openness can induce more arming relative to the autarkic outcome and result in lower welfare. Although the particular mechanisms at work in this alternative setting differ, their relevance for the welfare ranking of trade regimes similarly depends on how they influence the gains from trade relative to the costs of insecurity.
} 
Barbieri, K., (2002) The Liberal Illusion: Does Trade Promote Peace? Ann Arbor: The University of Michigan Press.

Barbieri, K. and Schneider, G., (1999) "Globalization and Peace: Assessing New Directions in the Study of Trade and Conflict," Journal of Peace Research 36(4), $387-404$.

Bhagwati, J., (1971) "The Generalized Theory of Distortions and Welfare," in Bhagwati, J., Jones, R., Mundell, R., Vanek, J. (eds.), Trade, Balance of Payments and Growth: Essays in Honor of Charles Kindleberger, Amsterdam: North-Holland.

Blomberg, S.B. and Hess, G.D., (2012) "The Economic Welfare Cost of Conflict: An Empirical Assessment," in Garfinkel, M.R. and Skaperdas, S. (eds), The Oxford Handbook of the Economics of Peace and Conflict, New York: Oxford University Press.

Brander, J.A. and Taylor, M.S., (1997a) "International Trade and Open Access Renewable Resources: The Small Open Economy Case," Canadian Journal of Economics $30(3), 526-552$.

Brander, J.A. and Taylor, M.S., (1997b) "International Trade between Consumer and Conservationist Countries," Resource and Energy Economics 19(4), 267-297.

Chichilnisky, G., (1994) "North-South Trade and the Global Environment," American Economic Review 84(4), 851-874.

Clark, D.J. and Riis, C., (1998) "Contest Success Functions: An Extension," Economic Theory 11, 201-204.

Dal Bo, E. and Dal Bo, P., (2011) "Workers, Warriors, and Criminals: Social Conflict in General Equilibrium," Journal of the European Economic Association 9, 646-77.

Demsetz, H., (1969) "Information and Efficiency: Another Viewpoint," Journal of Law and Economics 12(1), 1-22.

Dixit, A.K. and Norman, V., (1980) Theory of International Trade, Cambridge, England: Cambridge University Press.

Findlay, R. and 0'Rourke, H.K., (2007) Power and Plenty: Trade, War, and the World Economy in the Second Millennium, Princeton: Princeton University Press.

Garfinkel, M.R., Skaperdas S., and Syropoulos, C., (2008) "Globalization and Domestic Conflict," Journal of International Economics 76(2), 296-308. 
Hirshleifer, J., (1989) "Conflict and Rent-Seeking Success Functions: Ratio vs. Difference Models of Relative Success," Public Choice 63(2), 101-112.

Hirshleifer, J., (1991) "The Paradox of Power," Economics and Politics 3(3), 177-200.

Hotte, L., Long, N.V., and Tian, H., (2000) "International Trade with Endogenous Enforcement of Property Rights," Journal of Development Economics 62(1), 25-54.

Jones, R.W., (1965) "The Structure of Simple General Equilibrium Models," Journal of Political Economy 73(6), 557-572.

Kagan, D., (1995) On the Origins of War, New York: Doubleday.

Klare, M.T., (2001) Resource Wars: The New Landscape of Global Conflict, New York: Henry Holt and Company, LLC.

Kolstad, C.A. and Mathiesen, L., (1987) "Necessary and Sufficient Conditions for Uniqueness of a Cournot Equilibrium," Review of Economic Studies 54(4), 681-690.

Margolis, M.B. and Shogren, J.F., (2002) "Unprotected Resources and Voracious World Markets," Resources for the Future Discussion Paper 02.

Martin, P., Mayer, T., and Thoenig, M., (2008) "Make Trade Not War," Review of Economic Studies 75(3), 865-900.

Mehlum, H., Moene, K., and Torvik, R., (2006) "Institutions and the Resource Curse," Economic Journal 116(508), 1-20.

O'Rourke, H.K. and Williamson, J.G., (2000) "When Did Globalization Begin?" Working Paper 7632, National Bureau of Economic Research.

Robinson, J., Torvik, R., and Verdier, T., (2005) "Political Foundations of the Resource Curse," DELTA Working Paper 2003-33.

Rowe, D.M., (1999) "World Economic Expansion and National Security in Pre-World War I Europe," International Organization 53(2), 195-231.

Rowe, D.M., (2005) "The Tragedy of Liberalism How Globalization Caused the First World War," Security Studies 14(3), 407-447.

Rybczynski, T.M., (1955) "Factor Endowments and Relative Commodity Prices," Economica 22(88), 336-341.

Samuelson, P.A., (1949) "International Factor-Price Equalization Once Again," Economic Journal 59(234), 181-197. 
Skaperdas, S., (1996) "Contest Success Functions," Economic Theory 7(2), 283-290.

Skaperdas, S. and Syropoulos, C., (2001) "Guns, Butter, and Openness: On the Relationship between Security and Trade," American Economic Review: Papers and Proceedings 91(2), 353-357.

Skaperdas, S. and Syropoulos, C., (2002) "Insecure Property and the Efficiency of Exchange," Economic Journal 112(476), 133-146.

SIPRI (2005) Armaments, Disarmament and International Security Oxford: Oxford University Press.

Stiglitz, J.E. and Bilmes, L.J., (2012) "Estimating the Costs of War: Methodological Issues, with Applications to Iraq and Afghanistan," in Garfinkel, M.R. and Skaperdas, S. (eds), The Oxford Handbook of the Economics of Peace and Conflict New York: Oxford University Press.

Stolper, W. and Samuelson, P.A., (1941) "Protection and Real Wages," Review of Economic Studies 9(1), 58-73.

Torvik, R., (2002) "Natural Resources, Rent Seeking and Welfare," Journal of Development Economics 67(2), 455-470.

Tullock, G., (1980) "Efficient Rent Seeking," in Buchanan, J.M., Tollison, R.D. and Tullock, G. (eds), Toward a Theory of the Rent Seeking Society, College Station: Texas A\&M University Press, 3-15.

\section{A Appendix}

We first present several useful properties of the conflict technology in (1). For convenience, define $f_{i} \equiv f\left(G^{i}\right)$, where from our previous assumptions $f_{i}^{\prime}>0$ and $f_{i}^{\prime \prime} \leq 0$. Now, differentiate $\phi^{i}\left(G_{i}, G_{j}\right)$ with respect to its arguments, $G^{i}$ and $G^{j}$ for $i=1,2(j \neq i)$, to obtain the following:

$$
\begin{aligned}
\phi_{G^{i}}^{i} & =\frac{f_{i}^{\prime} f_{j}}{\left(f_{1}+f_{2}\right)^{2}}>0 \\
\phi_{G^{j}}^{i} & =-\frac{f_{j}^{\prime} f_{i}}{\left(f_{1}+f_{2}\right)^{2}}<0 \\
\phi_{G^{i} G^{i}}^{i} & =\frac{f_{j}}{\left(f_{1}+f_{2}\right)^{3}}\left[f_{i}^{\prime \prime}\left(f_{1}+f_{2}\right)-2\left(f_{i}^{\prime}\right)^{2}\right]<0 \\
\phi_{G^{i} G^{j}}^{i} & =\frac{\left(f_{i}-f_{j}\right) f_{i}^{\prime} f_{j}^{\prime}}{\left(f_{1}+f_{2}\right)^{3}} \gtrless 0 \text { if } G^{i} \gtrless G^{j} .
\end{aligned}
$$


Lemma A.1 If production in a country is diversified (i.e., $X_{j}^{i}>0$, for both countries $i=1,2$ and both goods $j=1,2$ ), then
(a) $\frac{\partial \omega^{i} / \partial p^{i}}{\omega^{i} / p^{i}} \lessgtr 0$ if $k_{2}^{i} \gtrless k_{1}^{i}$;
(b) $\frac{\partial R S^{i} / \partial p^{i}}{R S^{i} / p^{i}}>0$;
(c) $\frac{\partial R S^{i} / \partial k_{X}^{i}}{R S^{i} / k_{X}^{i}} \gtrless 0$ if $k_{2}^{i} \gtrless k_{1}^{i}$.

Proof: Following Jones (1965), we denote the shares of factor $h=K, L$ in the cost of producing good $j=1,2$ by $\theta_{h j}^{i}: \theta_{K j}^{i}=r^{i} a_{K j}^{i} / c_{j}^{i}$ and $\theta_{L j}^{i}=w^{i} a_{L j}^{i} / c_{j}^{i}$. Similarly, $\theta_{K G}^{i} \equiv$ $r^{i} \psi_{r}^{i} / \psi^{i}$ and $\theta_{L G}^{i} \equiv w^{i} \psi_{w}^{i} / \psi^{i}$ indicate the corresponding cost shares in guns. Now denote the amount of land and labor employed in industry $j=1,2$ respectively by $K_{j}^{i}$ and $L_{j}^{i}$. Then, these quantities as a fraction of resources remaining once land and labor for producing guns have been set aside are respectively indicated by $\lambda_{K j}^{i} \equiv K_{j}^{i} / K_{X}^{i}$ and $\lambda_{L j}^{i} \equiv L_{j}^{i} / L_{X}^{i}$. Finally, let a percentage change be indicated by a hat $\left({ }^{\wedge}\right)$ over the associated variable (e.g., $\left.\widehat{x}=\frac{d x}{x}\right)$.

Part (a): Noting that $c_{1}=1$ and $c_{2}=p$, differentiation of (2) and (3) totally gives

$$
\begin{array}{lll}
\frac{\partial c_{1}^{i}}{\partial w^{i}} d w^{i}+\frac{\partial c_{1}^{i}}{\partial r^{i}} d r^{i}=0 & \Longrightarrow & a_{L 1}^{i} \frac{w^{i}}{c_{1}^{i}} \frac{d w^{i}}{w^{i}}+a_{K 1}^{i} \frac{r^{i}}{c_{1}^{i}} \frac{d r^{i}}{r^{i}}=0 \\
\frac{\partial c_{2}^{i}}{\partial w^{i}} d w^{i}+\frac{\partial c_{2}^{i}}{\partial r^{i}} d r^{i}=d p^{i} & \Longrightarrow & a_{L 2}^{i} \frac{w^{i}}{c_{2}^{i}} \frac{d w^{i}}{w^{i}}+a_{K 2}^{i} \frac{r^{i}}{c_{2}^{i}} \frac{d r^{i}}{r^{i}}=\frac{d p^{i}}{p^{i}} .
\end{array}
$$

With the definitions given above, we can write this system of equations as

$$
\left(\begin{array}{cc}
\theta_{L 1}^{i} & \theta_{K 1}^{i} \\
\theta_{L 2}^{i} & \theta_{K 2}^{i}
\end{array}\right)\left(\begin{array}{c}
\widehat{w}^{i} \\
\widehat{r}^{i}
\end{array}\right)=\left(\begin{array}{c}
0 \\
\widehat{p}^{i}
\end{array}\right)
$$

Now, since $\sum_{h=K, L} \theta_{h j}=1$ for $j=1,2$ by definition, the determinant of the coefficient matrix above, denoted by $\left|\theta^{i}\right|$, can be written as

$$
\left|\theta^{i}\right| \equiv \theta_{K 2}^{i}-\theta_{K 1}^{i}=\theta_{L 1}^{i}-\theta_{L 2}^{i}=\frac{\omega^{i}\left(k_{2}^{i}-k_{1}^{i}\right)}{\left(\omega^{i}+k_{1}^{i}\right)\left(\omega^{i}+k_{2}^{i}\right)} \gtrless 0 \text { if } k_{2}^{i} \gtrless k_{1}^{i} \text {. }
$$

Then, solving (A.5) for the $p^{i}$-induced changes in factor prices yields

$$
\frac{p^{i} w_{p}^{i}}{w^{i}}=-\frac{\theta_{K 1}^{i}}{\left|\theta^{i}\right|} \quad \text { and } \quad \frac{p^{i} r_{p}^{i}}{r^{i}}=\frac{\theta_{L 1}^{i}}{\left|\theta^{i}\right|}
$$

From (A.6), then, we have $p^{i} \omega_{p}^{i} / \omega^{i}=p^{i} w_{p}^{i} / w^{i}-p^{i} r_{p}^{i} / r^{i}=-1 /\left|\theta^{i}\right| \lessgtr 0$ when $k_{2}^{i} \gtrless k_{1}^{i}$, which completes the proof to part (a).

Parts (b) and (c): Note first that we can combine (4) and (5) to obtain $\lambda_{L 1}^{i} k_{1}^{i}+\lambda_{L 2}^{i} k_{2}^{i}=k_{X}^{i}$. Then, following the strategy above in part (a), we differentiate (4) and (5) totally and solve 
the resulting system of equations to obtain

$$
\begin{aligned}
\widehat{X}_{1}^{i} & =\frac{1}{\left|\lambda^{i}\right|}\left(-\lambda_{L 2}^{i} \widehat{K}_{X}^{i}+\lambda_{K 2}^{i} \widehat{L}_{X}^{i}\right)-\frac{1}{\left|\lambda^{i}\right|\left|\theta^{i}\right|}\left(\lambda_{L 2}^{i} \delta_{K}^{i}+\lambda_{K 2}^{i} \delta_{L}^{i}\right) \widehat{p}^{i} \\
\widehat{X}_{2}^{i} & =\frac{1}{\left|\lambda^{i}\right|}\left(+\lambda_{L 1}^{i} \widehat{K}_{X}^{i}-\lambda_{K 1}^{i} \widehat{L}_{X}^{i}\right)+\frac{1}{\left|\lambda^{i}\right|\left|\theta^{i}\right|}\left(\lambda_{L 1}^{i} \delta_{K}^{i}+\lambda_{K 1}^{i} \delta_{L}^{i}\right) \widehat{p}^{i}
\end{aligned}
$$

where $\delta_{K}^{i} \equiv \lambda_{K 1}^{i} \theta_{L 1}^{i} \sigma_{1}^{i}+\lambda_{K 2}^{i} \theta_{L 2}^{i} \sigma_{2}^{i}>0$ and $\delta_{L}^{i} \equiv \lambda_{L 1}^{i} \theta_{K 1}^{i} \sigma_{1}^{i}+\lambda_{L 2}^{i} \theta_{K 2}^{i} \sigma_{2}^{i}>0$, with $\sigma_{j}^{i}=$ $c_{j}^{i} \frac{\partial^{2} c_{j}^{i}}{\partial w^{i} \partial r^{i}} / \frac{\partial c_{j}^{i}}{\partial w^{i}} \frac{\partial c_{j}^{i}}{\partial r^{i}}$ being the (absolute value of the) elasticity of substitution between land and labor in industry $j ;\left|\lambda^{i}\right|$ denotes the determinant of the coefficient matrix obtained from differentiating (4) and (5); recalling $\sum_{j=1,2} \lambda_{h j}^{i}=1$ for $h=K, L$, we have

$$
\left|\lambda^{i}\right| \equiv \lambda_{K 2}^{i}-\lambda_{L 2}^{i}=\lambda_{L 1}^{i}-\lambda_{K 1}^{i}=\frac{\left(k_{2}^{i}-k_{X}^{i}\right)\left(k_{X}^{i}-k_{1}^{i}\right)}{k_{X}^{i}\left(k_{2}^{i}-k_{1}^{i}\right)} \gtrless 0 \text { if } k_{2}^{i} \gtrless k_{1}^{i} \text {. }
$$

Now, observe that $\widehat{k}_{X}^{i}=\widehat{K}_{X}^{i}-\widehat{L}_{X}^{i}$, which implies

$$
\widehat{R S}^{i}=\widehat{X}_{2}^{i}-\widehat{X}_{1}^{i}=\frac{1}{\left|\lambda^{i}\right|} \widehat{k}_{X}^{i}+\frac{\delta_{K}^{i}+\delta_{L}^{i}}{\left|\lambda^{i}\right|\left|\theta^{i}\right|} \widehat{p}^{i}
$$

Inspection of (A.7) confirms parts (b) and (c). \|

In Lemma A.1 the residual land-labor ratio, $k_{X}^{i}$, is treated as exogenous. However, from (6) it is clear that $k_{X}^{i}$ depends on price, guns, and factor supplies. The next lemma clarifies this dependence.

Lemma A.2 Let $k^{i} \equiv \frac{K^{i}+\phi^{i} K_{0}}{L^{i}}$ and suppose the production of consumption goods is diversified. Then $k_{X}^{i}=k_{X}^{i}\left(p^{i}, G^{i}, G^{j} ; K_{0}, K^{i}, L^{i}\right)$ and

(a) $\frac{\partial k_{X}^{i}}{\partial p^{i}} \gtrless 0$ if $k_{2}^{i} \gtrless k_{1}^{i}$;

(b) $\frac{\partial k_{X}^{i}}{\partial G^{i}}>0, \forall G^{i}$ that satisfy $K_{0}^{i} \phi_{G^{i}}^{i}-\psi^{i} / r^{i}+\varepsilon>0$, for some $\varepsilon>0$;

(c) $\frac{\partial k_{X}^{i}}{\partial G^{j}}<0, \forall i \neq j$;

(d) $\frac{\partial k_{X}^{i}}{\partial G^{i}}+\frac{\partial k_{X}^{i}}{\partial G^{j}} \gtrless 0$ if $k^{i} \gtrless k_{G}^{i}$ whenever $G^{i}=G^{j}, \forall i \neq j$;

(e) $\frac{\partial k_{X}^{i}}{\partial L^{i}}<0$ and $\frac{\partial k_{X}^{i}}{\partial K_{0}}>0, \frac{\partial k_{X}^{i}}{\partial K^{i}}>0$.

Proof: Denote country $i$ 's land and labor shares in total net income $R^{i}$ by with $s_{K}^{i} \equiv$ $r^{i} K_{X}^{i} / R^{i}$ and $s_{L}^{i} \equiv w^{i} L_{X}^{i} / R^{i}$, and let $\sigma_{G}^{i}=\psi^{i} \psi_{w r}^{i} / \psi_{w}^{i} \psi_{r}^{i}$ be the (absolute value of the) elasticity of substitution between land and labor in the guns sector. Total differentiation of 
(6), using the linear homogeneity of $\psi^{i}$, yields

$$
\begin{aligned}
\widehat{k}_{X}^{i}= & \left(\frac{\psi^{i} \theta_{L G}^{i} \theta_{K G}^{i} \sigma_{G}^{i} G^{i}}{\left|\theta^{i}\right| R^{i} s_{K}^{i} s_{L}^{i}}\right) \widehat{p}^{i}+\frac{\psi^{i}}{R^{i} s_{K}^{i} s_{L}^{i}}\left[\frac{r^{i} s_{L}^{i}}{\psi^{i}}\left(K_{0} \phi_{G^{i}}^{i}-\frac{\psi^{i}}{r^{i}}\right)+\theta_{L G}^{i}\right] d G^{i} \\
& +\frac{r^{i} K_{0} \phi_{G^{j}}^{i}}{R^{i} s_{K}^{i}} d G^{j}+\frac{\phi^{i} d K_{0}}{K_{X}^{i}}+\frac{d K^{i}}{K_{X}^{i}}-\frac{d L^{i}}{L_{X}^{i}} .
\end{aligned}
$$

Parts (a)-(c) \& (e): The proofs follow from (A.8).

Part (d): Suppose $G^{i}=G^{j}$ so that $\phi_{G^{i}}^{i}=-\phi_{G^{j}}^{i}$. Now use $d G^{i}=d G^{j}$ in (A.8) to obtain

$$
\frac{\partial k_{X}^{i} / \partial G^{i}}{k_{X}^{i}}=\frac{\psi^{i}\left(\theta_{L G}^{i}-s_{L}^{i}\right)}{R^{i} s_{K}^{i} s_{L}^{i}} .
$$

Using the definitions of $\theta_{L G}^{i}, s_{L}^{i}$, and $R^{i}$, along with those for $K_{X}^{i}$ and $L_{X}^{i}$ in (4) and (5), tedious algebra verifies the following transformation of this relationship:

$$
\frac{\partial k_{X}^{i} / \partial G^{i}}{k_{X}^{i}}=\frac{\psi^{i}\left(\theta_{L G}^{i}-s_{L}^{i}\right)}{R^{i} s_{K}^{i} s_{L}^{i}}=\frac{\psi_{w}^{i}\left(k_{X}^{i}-k_{G}^{i}\right)}{K_{X}^{i}}=\frac{\psi_{w}^{i} L^{i}\left(k^{i}-k_{G}^{i}\right)}{K_{X}^{i} L_{X}^{i}} .
$$

Inspection of this expression confirms part (d). \|

Lemma A.3 Each country $i$ 's indirect utility function, $V^{i}$, has the following properties:

(a) $V_{G^{i} G^{i}}^{i}<0$;

(b) $V_{G^{i} G^{j}}^{i} \gtrless 0$ if $G^{i} \gtrless G^{j}, j \neq i$;

(c) $V_{G^{i} p^{i}}^{i} \gtrless 0$ if $k_{2}^{i} \gtrless k_{1}^{i}$ when evaluated at the value of $G^{i}$ that solves $V_{G^{i}}^{i}=0$;

(d) $V^{i}$ is strictly quasi-convex in $p^{i}$, and is minimized at the value of $p^{i}$ that solves $M^{i}=0$.

\section{Proof:}

Part (a): Differentiate (9) with respect to $G^{i}$ and use equation (A.3) to obtain

$$
V_{G^{i} G^{i}}^{i}=\mu^{i} r^{i} K_{0} \phi_{G^{i} G^{i}}^{i}<0
$$

Part (b): Differentiation of (9) with respect to $G^{j}$, using equation (A.4), gives

$$
V_{G^{i} G^{j}}^{i}=\mu^{i} r^{i} K_{0} \phi_{G^{i} G^{j}}^{i} \gtrless 0 \quad \text { if } \quad G^{i} \gtrless G^{j}
$$

Part (c): As noted in the text, $\psi^{i} / r^{i}=\psi\left(\omega^{i}, 1\right)$, implying that $\partial\left(\psi^{i} / r^{i}\right) / \partial p^{i}=\psi_{w}^{i} \omega_{p}^{i}$. Then, differentiating (9) with respect to price and evaluating the resulting expression at 
the optimum gives (by Lemma A.1(a))

$$
\begin{aligned}
V_{G^{i} p^{i}}^{i} & =-\mu^{i} r^{i} \frac{\partial\left(\psi^{i} / r^{i}\right)}{\partial p^{i}}=-\mu^{i}\left(\frac{\psi^{i}}{p^{i}}\right)\left(\frac{w^{i} \psi_{w}^{i}}{\psi^{i}}\right)\left(\frac{p^{i} \omega_{p}^{i}}{\omega^{i}}\right) \\
& =\mu^{i}\left(\frac{\psi^{i}}{p^{i}}\right) \frac{\theta_{L G}^{i}}{\left|\theta^{i}\right|} \gtrless 0 \quad \text { if } \quad k_{2}^{i} \gtrless k_{1}^{i} .
\end{aligned}
$$

Part (d): This is a standard property of indirect (trade) utility functions, highlighting the important idea that, for given guns, a country's welfare is higher, the greater is the deviation of product prices from their autarkic levels (Dixit and Norman, 1980). ॥

Lemma A.4 Under autarky, country $i$ 's market clearing price of the non-numeraire good, $p_{A}^{i}$, and its residual land-labor ratio, $k_{X}^{i}$, are related as follows:

$$
\frac{\partial p_{A}^{i}}{\partial k_{X}^{i}} \lessgtr 0 \quad \text { if } k_{2}^{i} \gtrless k_{1}^{i} .
$$

We thus have for each country $i=1,2$

(a) $\frac{\partial p_{A}^{i}}{\partial G^{i}} \lessgtr 0$ if $k_{2}^{i} \gtrless k_{1}^{i}, \forall G^{i}$ that satisfy $V_{G^{i}}^{i}+\varepsilon>0$, for some $\varepsilon>0$;

(b) $\frac{\partial p_{A}^{i}}{\partial G^{j}} \gtrless 0$ if $k_{2}^{i} \gtrless k_{1}^{i}(j \neq i)$;

(c) $\left(k_{2}^{i}-k_{1}^{i}\right)\left(\frac{\partial p_{A}^{i}}{\partial G^{i}}+\frac{\partial p_{A}^{i}}{\partial G^{j}}\right) \lessgtr 0$ for $G^{i}=G^{j} \quad(j \neq i)$ if $k_{G}^{i} \lessgtr k^{i} \equiv \frac{K^{i}+\phi^{i} K_{0}}{L^{i}}$;

(d) $\frac{\partial p_{A}^{i}}{\partial L^{i}} \gtrless 0, \frac{\partial p_{A}^{i}}{\partial K_{0}} \lessgtr 0$, and $\frac{\partial p_{A}^{i}}{\partial K^{i}} \lessgtr 0$ if $k_{2}^{i} \gtrless k_{1}^{i}$.

Proof: Let $\sigma_{D}^{i}>0$ be the elasticity of substitution in consumption. Focusing on percentage changes, note that $\widehat{R D}^{i}=-\sigma_{D}^{i} \widehat{p}^{i}$ and that the expression for $\widehat{R S}^{i}$ is given in (A.7). Totally differentiating (10) and rearranging terms gives

$$
\widehat{R D}^{i}=\widehat{R S}^{i} \Longrightarrow\left(\sigma_{D}^{i}+\frac{\delta_{K}^{i}+\delta_{L}^{i}}{\left|\lambda^{i}\right|\left|\theta^{i}\right|}\right) \widehat{p}^{i}+\frac{1}{\left|\lambda^{i}\right|} \widehat{k}_{X}^{i}=0
$$

The above relation and the definitions of $\left|\theta^{i}\right|$ and $\left|\lambda^{i}\right|$ reveal that $p^{i}$ is decreasing (increasing) in $k_{X}^{i}$ if $k_{2}^{i}>k_{1}^{i}\left(k_{2}^{i}<k_{1}^{i}\right)$. Combining the expression for $\hat{k}_{X}^{i}$ in (A.8) with the above expression gives

$$
\widehat{p}_{A}^{i}=-\frac{1}{\Delta^{i}\left|\lambda^{i}\right|}\left[\frac{\partial k_{X}^{i} / \partial G^{i}}{k_{X}^{i}} d G^{i}+\frac{\partial k_{X}^{i} / \partial G^{j}}{k_{X}^{i}} d G^{j}+\frac{\phi^{i} d K_{0}}{K_{X}^{i}}+\frac{d K^{i}}{K_{X}^{i}}-\frac{d L^{i}}{L_{X}^{i}}\right]
$$

where $\Delta^{i} \equiv \sigma_{D}^{i}+\frac{\delta_{K}^{i}+\delta_{L}^{i}}{\left|\lambda^{i}\right|\left|\theta^{i}\right|}+\frac{\psi^{i} \theta_{L G}^{i} \theta_{K G}^{i} \sigma_{G}^{i}}{\left|\lambda^{i}\right|\left|\theta^{i}\right| R^{i} s_{K}^{i} s_{L}^{i}} G^{i}>0$. The proofs to parts (a)-(d) now follow from (A.13) and Lemma A.2. $\|$ 
Theorem A.1 An interior Nash equilibrium in pure strategies (security policies) exists under autarky. Furthermore, the equilibrium is unique if the technology for arms is sufficiently labor intensive or the inputs to arms are not very close complements.

\section{Proof:}

Existence: We establish existence of equilibrium in pure strategies, by showing that each country $i$ 's payoff function $V_{A}^{i}$ is strictly quasi-concave in its strategy, $G^{i}$. To do so, it is sufficient to show either that $V_{A}^{i}$ is strictly monotonic in $G^{i}$ or that $V_{A}^{i}$ is first strictly increasing and then strictly decreasing over the agent's strategy space.

Let $F\left(K_{G}^{i}, L_{G}^{i}\right)$ be the production function for guns that is dual to the unit cost function $\psi\left(w^{i}, r^{i}\right)$ and define $\bar{G}^{i} \equiv F\left(K^{i}, L^{i}\right)$ as the level of guns produced with the country's entire secure endowments of land and labor. Country $i$ 's strategy space is $\left[0, \bar{G}^{i}\right]$. For any $G^{j} \in\left[0, \bar{G}^{j}\right]$, if $G^{i}=\bar{G}^{i}$, country $i(\neq j)$ will not be able to produce either of the consumption goods; therefore, $V_{A}^{i}\left(\bar{G}^{i}, G^{j}\right)<V_{A}^{i}\left(G^{i}, G^{j}\right)$ for any $G^{i} \in\left[0, \bar{G}^{i}\right)$ which implies that, under autarky, no country will use all of its resources to produce arms. Furthermore, since $\lim _{G^{i} \rightarrow 0} f^{\prime}\left(G^{i}\right)=\infty$ by assumption, we must have $\partial V_{A}^{i} / \partial G^{i}>0$ as $G^{i} \rightarrow 0$. By the continuity of $V_{A}^{i}$ in $G^{i}$, there will exist a best response function for each country $i, B_{A}^{i}\left(G^{j}\right) \equiv \min \left\{G^{i} \in\left(0, \bar{G}^{i}\right) \mid \partial V_{A}^{i} / \partial G^{i}=0\right\}$, with the property that $\partial V_{A}^{i} / \partial G^{i}>0$ $\forall G^{i}<B_{A}^{i}\left(G^{j}\right)$. Thus, to establish strict quasi-concavity of $V_{A}^{i}$ in $G^{i}$ we need only to prove that $\partial V_{A}^{i} / \partial G^{i}<0, \forall G^{i}>B_{A}^{i}\left(G^{j}\right)$.

Suppose, on the contrary, that $\partial V_{A}^{i} / \partial G^{i} \geq 0$. Since $V_{A}^{i}$ must eventually fall to $V_{A}^{i}\left(\bar{G}^{i}, G^{j}\right)$, this supposition implies that $V_{A}^{i}$ must attain a local minimum at some $G^{i}>B^{i}\left(G^{j}\right)$, which would imply that $\partial^{2} V_{A}^{i} /\left(\partial G^{i}\right)^{2}>0$. We now establish that this is not possible. Recalling that $p_{A}^{i}=p_{A}^{i}\left(G^{i}, G^{j}\right)$ under autarky and that $\omega^{i}=\omega\left(p^{i}\right)$, we differentiate (9) with respect to $G^{i}$ and apply (9) to the resulting expression to obtain ${ }^{42}$

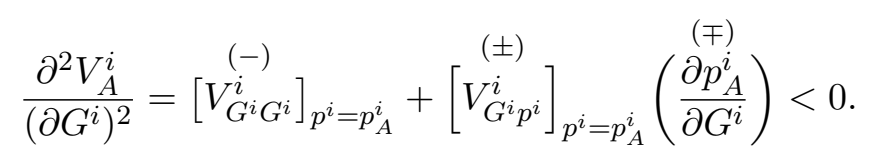

By Lemma A.3(a), the first term in the RHS of the above expression is negative regardless of the ranking of factor intensities. Furthermore, by Lemmas A.3(c) and A.4(b), the product of the expressions in the second term will also be negative. It follows that $\partial^{2} V_{A}^{i} /\left(\partial G^{i}\right)^{2}<0$ at any $G^{i}$ where $\partial V_{A}^{i} / \partial G^{i}=0$ regardless of the ranking of factor intensities. This proves $B_{A}^{i}\left(G^{j}\right)$ is unique and establishes the existence of a pure-strategy equilibrium.

Uniqueness: Having already established that guns production is bounded (i.e., $B_{A}^{i}\left(G^{j}\right) \in$ $\left(0, \bar{G}^{i}\right)$ for $i=1,2(j \neq i)$, we can now establish uniqueness of equilibrium by showing that,

\footnotetext{
${ }^{42}$ In this expression and below, the top signs in " \pm " and “干” apply when $k_{2}^{i}>k_{1}^{i}$ and the bottom signs apply when $k_{2}^{i}<k_{1}^{i}$.
} 
at any equilibrium point, the determinant of the Jacobian of the net marginal payoffs in (9) is positive -i.e., $|J|=\frac{\partial^{2} V_{A}^{1}}{\left(\partial G^{1}\right)^{2}} \frac{\partial^{2} V_{A}^{2}}{\left(\partial G^{2}\right)^{2}}-\frac{\partial^{2} V_{A}^{1}}{\partial G^{1} \partial G^{2}} \frac{\partial^{2} V_{A}^{2}}{\partial G^{2} \partial G^{1}}>0$ (Kolstad and Mathiesen, 1987).

Consider an equilibrium point where $G_{A}^{1 *}=B_{A}^{1}\left(G_{A}^{2 *}\right)$ and $G_{A}^{2 *}=B_{A}^{1}\left(G_{A}^{1 *}\right)$. From the expression for $|J|$, it can be seen that, if the product of the slopes of the two countries' best response functions, $\left(\partial B_{A}^{1} / \partial G^{2}\right)\left(\partial B_{A}^{2} / \partial G^{1}\right)$, is less than 1 at $\left(G_{A}^{1 *}, G_{A}^{2 *}\right)$, then $|J|>0$, implying that this equilibrium is unique. The slope of country $i$ 's best-response function can be written as

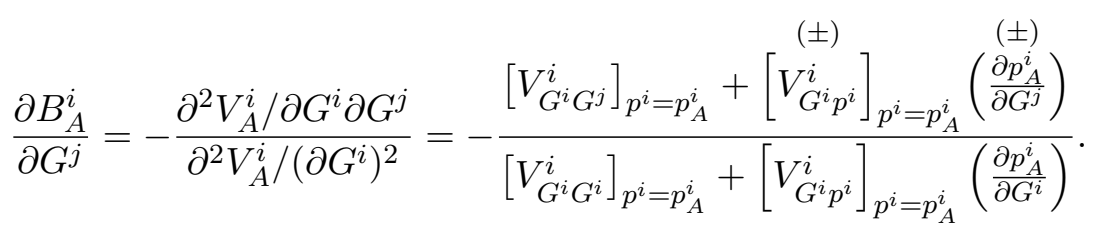

Since $\partial^{2} V_{A}^{i} /\left(\partial G^{i}\right)^{2}<0$ as shown in (A.14), the sign of $\partial B_{A}^{i} / \partial G^{j}$ is determined by the sign of $\partial^{2} V_{A}^{i} / \partial G^{i} \partial G^{j}$ shown in the numerator of (A.15). Now, by Lemmas A.3(c) and A.4(b), the second term of the numerator of the RHS of this expression is always positive. By Lemma A.3(b), the first term in the numerator is positive if $B_{A}^{i}\left(G^{j}\right)>G^{j}$ (also see equation (A.11)), in which case $G^{i}$ is a strategic complement for $G^{j}$. However, if $B_{A}^{i}\left(G^{j}\right)<G^{j}$, then the first term is negative. Thus, when $B_{A}^{i}\left(G^{j}\right)$ is sufficiently smaller than $G^{j}, G^{i}$ can become a strategic substitute for $G^{j}$. Furthermore, since $\phi_{G^{1} G^{2}}^{1}=-\phi_{G^{2} G^{1}}^{2}$ (see (A.4)), it follows from (A.11) that $\operatorname{sign}\left[V_{G^{1} G^{2}}^{1}\right]_{p^{1}=p_{A}^{1}}=-\operatorname{sign}\left[V_{G^{2} G^{1}}^{2}\right]_{p^{2}=p_{A}^{2}}$. Therefore, we have two possibilities to consider. Either (i) $\partial B_{A}^{i} / \partial G^{j}>0$ and $\partial B_{A}^{j} / \partial G^{i} \leq 0$ for $i=1,2$ $(j \neq i)$; or, (ii) $\partial B_{A}^{i} / \partial G^{j}>0$ for $i=1,2(j \neq i)$. It is easy to check that, in case (i), $\left(\partial B_{A}^{1} / \partial G^{2}\right)\left(\partial B_{A}^{2} / \partial G^{1}\right)<1$ and therefore $|J|>0$. Turning to case (ii), we now establish the existence of (sufficient) conditions that ensure $\left(\partial B_{A}^{1} / \partial G^{2}\right)\left(\partial B_{A}^{2} / \partial G^{1}\right)<1$ and thus $|J|>0 .{ }^{43}$

To proceed, use (A.8) and (A.13), applying (9), to obtain

$$
\frac{\partial p_{A}^{i}}{\partial G^{i}}=-\frac{p_{A}^{i} \psi^{i} \theta_{L G}^{i}}{\Delta^{i}\left|\lambda^{i}\right| R^{i} s_{K}^{i} s_{L}^{i}} \quad \text { and } \quad \frac{\partial p_{A}^{i}}{\partial G^{j}}=\frac{p_{A}^{i} \psi^{i}}{\Delta^{i}\left|\lambda^{i}\right| R^{i} s_{K}^{i} s_{L}^{i}}\left(-\frac{\phi_{G^{j}}^{i}}{\phi_{G^{i}}^{i}}\right) s_{L}^{i}
$$

The above expressions together with (9), (A.10), (A.11), and (A.12) can be substituted into (A.15) to obtain $\partial B_{A}^{i} / \partial G^{j}=-\left(\phi_{G^{j}}^{i} / \phi_{G^{i}}^{i}\right) \Gamma_{A}^{i}$, where

$$
\Gamma_{A}^{i}=\left[-\frac{\phi_{G^{i} G^{j}}^{i} \Delta^{i}}{\phi_{G^{j}}^{i}}+\frac{\psi^{i} \theta_{L G}^{i} s_{L}^{i}}{\left|\lambda^{i}\right|\left|\theta^{i}\right| R^{i} s_{K}^{i} s_{L}^{i}}\right] /\left[-\frac{\phi_{G^{i} G^{i}}^{i} \Delta^{i}}{\phi_{G^{i}}^{i}}+\frac{\psi^{i}\left(\theta_{L G}^{i}\right)^{2}}{\left|\lambda^{i}\right|\left|\theta^{i}\right| R^{i} s_{K}^{i} s_{L}^{i}}\right] .
$$

\footnotetext{
${ }^{43}$ Note that, in case (ii), $|J|>0$ is also the condition for local stability of equilibrium.
} 
From equations (A.1) and (A.2), we have $\left(\phi_{G^{2}}^{1} / \phi_{G^{1}}^{1}\right)\left(\phi_{G^{1}}^{2} / \phi_{G^{2}}^{2}\right)=1$, implying $\left(\partial B_{A}^{1} / \partial G^{2}\right)$. $\left(\partial B_{A}^{2} / \partial G^{1}\right)=\Gamma_{A}^{1} \Gamma_{A}^{2}$; therefore, if $\Gamma_{A}^{i} \in(0,1)$ for $i=1,2$, then $|J|>0$. In case (ii), both the numerator and the denominator of $\Gamma_{A}^{i}$ are positive, so $\Gamma_{A}^{i}>0$. Now define $\eta^{i} \equiv G^{i}\left[-\phi_{G^{i} G^{i}}^{i} / \phi_{G^{i}}^{i}+\phi_{G^{i} G^{j}}^{i} / \phi_{G^{j}}^{i}\right]$. From (A.1)-(A.4), $\eta^{i}=G^{i}\left[f_{i}^{\prime} / f_{i}-f_{i}^{\prime \prime} / f_{i}^{\prime}\right]>0$. Then, subtracting the numerator of $\Gamma_{A}^{i}$ from its denominator while using the definition of $\Delta^{i}$ shown below (A.13) gives the following:

$$
\frac{\eta^{i}}{G^{i}}\left(\sigma_{D}^{i}+\frac{\delta_{K}^{i}+\delta_{L}^{i}}{\left|\lambda^{i}\right|\left|\theta^{i}\right|}\right)+\frac{\psi^{i} \theta_{L G}^{i}}{\left|\lambda^{i}\right|\left|\theta^{i}\right| R^{i} s_{K}^{i} s_{L}^{i}}\left(\theta_{L G}^{i}+\theta_{K G}^{i} \sigma_{G}^{i} \eta^{i}-s_{L}^{i}\right) .
$$

Clearly, a sufficient condition for $\Gamma_{A}^{i}<1$ is that (A.17) is positive, which is almost always true. In particular, since the first term and the coefficient in front of the second term are unambiguously positive, a sufficient (but hardly necessary) condition for $\Gamma_{A}^{i}<1$ is $\theta_{L G}^{i}+\theta_{K G}^{i} \sigma_{G}^{i} \eta^{i}-s_{L}^{i} \geq 0$ or equivalently $\theta_{L G}^{i}\left(1-s_{L}^{i}\right)+\theta_{K G}^{i}\left(\sigma_{G}^{i} \eta^{i}-s_{L}^{i}\right) \geq 0$. This condition is satisfied under a wide range of circumstances, ${ }^{44}$ including: (i) $\sigma_{G}^{i} \eta^{i} \geq s_{L}^{i}$, which requires arms inputs not to be close complements; and (ii) $\theta_{L G}^{i} \geq s_{L}^{i}$ (or, by (A.9), $k^{i}>k_{G}^{i}$ ), which requires the guns sector to be sufficiently labor intensive, regardless of the degree of substitutability between inputs in arms. Either condition, along with the boundary conditions established above, ensures uniqueness of equilibrium. \|

Lemma A.5 Under autarky, equilibrium product prices and security policies satisfy the following inequalities:

$$
\left(k_{2}^{i}-k_{1}^{i}\right)\left(p_{A}^{1 *}-p_{A}^{2 *}\right) \gtrless 0 \Longleftrightarrow G_{A}^{1 *} \gtrless G_{A}^{2 *} .
$$

Proof: In (9) we can use (A.1) and the fact that $M C^{i}=\psi^{i} / r^{i}=\psi\left(\omega\left(p^{i}\right), 1\right)$ to obtain

$$
\frac{M B^{1}}{M B^{2}}=\frac{f^{\prime}\left(G^{1}\right) / f\left(G^{1}\right)}{f^{\prime}\left(G^{2}\right) / f\left(G^{2}\right)}=\frac{\psi\left(\omega\left(p^{1}\right), 1\right)}{\psi\left(\omega\left(p^{2}\right), 1\right)}=\frac{M C^{1}}{M C^{2}},
$$

where for simplicity we have omitted stars. Now if $k_{2}^{i}>k_{1}^{i}$, then by Lemma A.1(a), $\psi\left(\omega\left(p^{i}\right), 1\right)$ is decreasing in $p^{i}$; therefore, if $p^{1} \gtrless p^{2}, M C^{1} / M C^{2} \lessgtr 1$, which by the above equation requires $M B^{1} / M B^{2} \lessgtr 1$; in turn, the concavity of $f(\cdot)$ implies $G^{1} \gtrless G^{2}$. Alternatively, if $k_{2}^{i}<k_{1}^{i}, \psi_{\omega}^{i} \omega_{p}^{i}>0$ (Lemma A.1(a)), which implies $M C^{1} / M C^{2} \gtrless 1$ if $p^{1} \gtrless p^{2}$. But then $M B^{1} / M B^{2} \gtrless 1$ which requires $G^{1} \lessgtr G^{2}$.

Proof of Lemma 1. Since the logic behind part (a) was outlined in the main text, here we prove part (b). A redistribution of a secure resource from country $j$ to country $i(\neq j)$ expands (contracts) the "recipient" ("donor") country's resource endowment. Differentiating

\footnotetext{
${ }^{44}$ If, for example, the production function for guns is Cobb-Douglas and the conflict technology takes the Tullock form (i.e., $\left.f\left(G^{i}\right)=\left(G^{i}\right)^{\gamma}, \forall \gamma \in(0,1]\right)$, then $\sigma_{G}^{i}=1$ and $\eta^{i}=1$, thus implying that the sufficient condition simplifies to $1-s_{L}^{i} \geq 0$, which is always satisfied.
} 
country $i$ 's FOC condition in (9) appropriately gives

$$
\frac{\partial^{2} V_{A}^{i}}{\left(\partial G^{i}\right)^{2}} d B_{A}^{i}+\frac{\partial^{2} V_{A}^{i}}{\partial G^{i} \partial H^{i}} d H^{i}=0 \Longrightarrow \frac{d B_{A}^{i}}{d H^{i}}=-\frac{\partial^{2} V_{A}^{i} / \partial G^{i} \partial H^{i}}{\partial^{2} V_{A}^{i} /\left(\partial G^{i}\right)^{2}}
$$

for $H=L, K$. Since $\partial^{2} V_{A}^{i} /\left(\partial G^{i}\right)^{2}<0$, we have $\operatorname{sign}\left[d B_{A}^{i} / d H^{i}\right]=\operatorname{sign}\left[\partial^{2} V_{A}^{i} / \partial G^{i} \partial H^{i}\right]$. Differentiation of (9) yields

$$
\frac{\partial^{2} V_{A}^{i}}{\partial G^{i} \partial H^{i}}=\left[V_{G^{i} p^{i}}^{i}\right]_{p^{i}=p_{A}^{i}} \frac{d p_{A}^{i}}{d H^{i}}
$$

From Lemma A.3(c) and Lemma A.4(d), it follows that, regardless of the ranking of $k_{1}^{i}$ and $k_{2}^{i}, d B_{A}^{i} / d L^{i}>0$ whereas $d B_{A}^{i} / d K^{i}<0$. The signs of these derivatives imply that a transfer of labor from one country to another increases (decreases) arms production by the recipient (donor) for any given arms choice by the rival; yet, a transfer of land decreases (increases) arms production by the recipient (donor). By the properties of best-response functions and in particular the uniqueness of equilibrium (shown above), if we start with an arbitrary secure endowment configuration in $\mathcal{S}^{0}$ and transfer a small amount of labor from country $j$ to country $i$ or land from country $i$ to country $j$, we necessarily end up somewhere in $\mathcal{S}^{i}$ where $G_{A}^{i *}>G_{A}^{j *}$. We must also have, by Lemma A.5 $p_{A}^{i *} \gtrless p_{A}^{j *}$ if $k_{2}^{i} \gtrless k_{1}^{i}$, and by Lemma A.4 $k_{X}^{i *}<k_{X}^{j *}$. Notice that this proof does not require we obtain complete comparative statics results on equilibrium arming and applies for all secure resource allocations in $\mathcal{S}^{i}$. $\|$

Lemma A.6 (Transfers of Secure Resources) For initial factor distributions in $\mathcal{S}^{0}$, a small transfer of a secure resource from country $j$ to its adversary $i(\neq j)$ has the following implications for arming and welfare under autarky:

(a) $\frac{d G_{A}^{i *}}{d L^{i}}=-\frac{d G_{A}^{j *}}{d L^{i}}>0$ but $\frac{d G_{A}^{i *}}{d K^{i}}=-\frac{d G_{A}^{j *}}{d K^{i}}<0$;

(b) $\frac{d V_{A}^{i *}}{d L^{i}}=-\frac{d V_{A}^{j *}}{d L^{i}}>\mu\left(\widetilde{p}_{A}^{*}\right) w\left(\widetilde{p}_{A}^{*}\right)$ but $\frac{d V_{A}^{i *}}{d K^{i}}=-\frac{d V_{A}^{j *}}{d K^{i}}<\mu\left(\widetilde{p}_{A}^{*}\right) r\left(\widetilde{p}_{A}^{*}\right)$.

Proof: To identify the effects of endowment changes on equilibrium security policies we differentiate the FOCs in (9) and solve the resulting system of equations to obtain

$$
\left(\begin{array}{c}
d G_{A}^{1 *} \\
d G_{A}^{2 *}
\end{array}\right)=\frac{1}{|J|}\left(\begin{array}{rr}
\frac{\partial^{2} V_{A}^{2}}{\left(\partial G^{2}\right)^{2}} & -\frac{\partial^{2} V_{A}^{1}}{\partial G^{1} \partial G^{2}} \\
-\frac{\partial^{2} V_{A}^{2}}{\partial G^{2} \partial G^{1}} & \frac{\partial^{2} V_{A}^{1}}{\left(\partial G^{1}\right)^{2}}
\end{array}\right)\left(\begin{array}{c}
-\frac{\partial^{2} V_{A}^{1}}{\partial G^{1} \partial H^{1}} d H^{1} \\
-\frac{\partial^{2} V_{A}^{2}}{\partial G^{2} \partial H^{2}} d H^{2}
\end{array}\right)
$$

for $H^{i}=L^{i}, K^{i}$ where $|J|>0$ and all expressions are evaluated at the equilibrium. Start with an endowment distribution in $\mathcal{S}^{0}$, so that $G_{A}^{i *}=\widetilde{G}_{A}^{*}$ and $p_{A}^{i *}=\widetilde{p}_{A}^{*}$ for $i=1,2$. At such a distribution and prices, we have the following: 
(i) $\frac{\partial^{2} V_{A}^{1}}{\partial G^{1} \partial G^{2}}=\frac{\partial^{2} V_{A}^{2}}{\partial G^{2} \partial G^{1}}>0$ since by Lemma A.3(b), $V_{G^{1} G^{2}}^{1}=V_{G^{2} G^{1}}^{2}=0($ see $(\mathrm{A} .15))$;

(ii) $\frac{\partial^{2} V_{A}^{1}}{\left(\partial G^{1}\right)^{2}}=\frac{\partial^{2} V_{A}^{2}}{\left(\partial G^{2}\right)^{2}}<0$ by $($ A.14);

(iii) $\frac{\partial B_{A}^{1}}{\partial G^{2}}=-\frac{\partial^{2} V_{A}^{1} / \partial G^{1} \partial G^{2}}{\partial^{2} V_{A}^{1} /\left(\partial G^{1}\right)^{2}}=-\left(\phi_{G^{2}}^{1} / \phi_{G^{1}}^{1}\right) \Gamma_{A}^{1}=\Gamma_{A}^{1} \in(0,1)$ by (A.15), (A.16) and the related discussion in the proof of Theorem A.1; and,

(iv) $\frac{\partial^{2} V_{A}^{1}}{\partial G^{1} \partial L^{1}}=\frac{\partial^{2} V_{A}^{2}}{\partial G^{2} \partial L^{2}}>0$ whereas $\frac{\partial^{2} V_{A}^{1}}{\partial G^{1} \partial K^{1}}=\frac{\partial^{2} V_{A}^{2}}{\partial G^{2} \partial K^{2}}<0$ by (A.18) and the related discussion.

Part (a): Consider a small transfer of labor from country 2 to country 1 , so that $-d L^{2}=$ $d L^{1}>0$. Using the above observations with (A.19) yields

$$
\frac{d G_{A}^{1 *}}{d L^{1}}=-\frac{d G_{A}^{2 *}}{d L^{1}}=\frac{\stackrel{(+)}{1}}{|J|}\left[-\frac{\stackrel{(+)}{2}^{2} V_{A}^{1}}{\left(\partial G^{1}\right)^{2}}\right]\left(1-\stackrel{\stackrel{(+)}{\partial B_{A}^{1}}}{\partial G^{2}}\right)\left(\frac{\partial^{2} V_{A}^{1}}{\partial G^{1} \partial L^{1}}\right)>0 .
$$

Similar logic for land redistributions shows that $d G_{A}^{1 *} / d K^{1}=-d G_{A}^{2 *} / d K^{1}<0$.

Part (b): Extend the decomposition of welfare effects in (8) to include the effect of changes in the countries' secure holdings of resources. Focusing on labor redistributions, invoking the envelope theorem and using the fact that $M^{i}=0$ under autarky yield

$$
\frac{d V_{A}^{i *}}{d L^{i}}=\mu\left(p_{A}^{i *}\right)\left[w\left(p_{A}^{i *}\right)+r\left(p_{A}^{i *}\right) K_{0} \phi_{G^{j}}^{i} \frac{d G_{A}^{j *}}{d L^{i}}\right] \text { for } i=1,2(j \neq i),
$$

where $p_{A}^{i *}=\widetilde{p}_{A}^{*}$ for initial distributions in $\mathcal{S}^{0}$. Then, part (b) of the lemma is established by invoking symmetry and applying part (a) of the lemma to (A.20) and an analogous expression for the welfare effects of a change in land. \|

Theorem A.2 If the world price, technology, the distribution of secure endowments and the degree of land insecurity are such that (i) free trade in consumption goods leads to international factor price equalization, and (ii) the production of arms does not exhaust either country's secure land endowment, an interior pure strategy, Nash equilibrium in security policies will exist, and will be unique and symmetric.

Proof: The proofs for existence and uniqueness of equilibrium, which build on parts (a) and (b) of Lemma A.3, are similar to (and simpler than) those in the case of autarky (see above), and are thus omitted here. The main text provides a discussion of the logic underlying the symmetry results. \|

Proposition A.1 In the case of identical countries, conflict imparts a positive bias, relative to the hypothetical case of no conflict, on each country's tendency to export (import) the good produced intensively with land if guns production is sufficiently labor (land) intensive. 
Proof: Under free trade with $p^{i}=\pi$, country $i$ 's excess demand for good 2 is

$$
M^{i}=D_{2}^{i}-X_{2}^{i}=D_{2}^{i}\left(\pi, R^{i}\left(\pi, K_{X}^{i}, L_{X}^{i}\right)\right)-R_{\pi}^{i}\left(\pi, K_{X}^{i}, L_{X}^{i}\right)
$$

The effect of conflict on a country's imports and hence exports can be identified by differentiating the expression above with respect to $G^{i}$. (We thus move from Nirvana to a situation of some conflict.) Total differentiation of (A.21) keeping the world price fixed yields

$$
d M^{i}=\frac{\partial D_{2}^{i}}{\partial R^{i}}\left[R_{K}^{i} d K_{X}^{i}+R_{L}^{i} d L_{X}^{i}\right]-R_{\pi K}^{i} d K_{X}^{i}-R_{\pi L}^{i} d L_{X}^{i}
$$

The first term in the RHS of the above expression is an income effect. Since our focus here is on the case of identical countries, an increase in $G^{i}$ would be matched by an equal increase in $G^{j}$, and so would result in a decrease in income and thus a decrease in the demand for good 2. The last two terms combined represent a production effect, as an increase in $G^{i}$ and an equal increase in $G^{j}$ influence country $i$ residual factor endowments.

To proceed, recall that $D_{2}^{i}=\alpha_{D}^{i} R^{i} / p^{i}$ where $\alpha_{D}^{i} \equiv-\frac{\pi \mu_{p}^{i}}{\mu^{i}} \in(0,1)$ is country $i$ 's expenditure share on good 2 . Under the assumption that the country trades freely so that $p^{i}=\pi$, these relationships imply $\frac{\partial D_{2}^{i}}{\partial R^{i}}=\alpha_{D}^{i} / \pi$. Furthermore, by the properties of the revenue function with $p^{i}=\pi$, we have $R_{K}^{i}=r^{i}, R_{L}^{i}=w^{i}, R_{\pi K}^{i}=R_{K \pi}^{i}=r_{\pi}^{i}$ and $R_{\pi L}^{i}=w_{\pi}^{i}$. Assuming $d G^{i}=d G^{j}=d G$ (which implies $\phi_{G^{i}}^{i}=-\phi_{G^{j}}^{i}$ ) and keeping in mind that $K_{X}^{i}=K^{i}+\phi^{i} K_{0}-\psi_{r}^{i} G^{i}$ and $L_{X}^{i}=L^{i}-\psi_{w}^{i} G^{i}$, equation (A.22) can be written as

$$
d M^{i}=\left[\frac{1}{\pi} \alpha_{D}^{i}\left(-\psi^{i}\right)+\left(r_{\pi}^{i} \psi_{r}^{i}+w_{\pi}^{i} \psi_{w}^{i}\right)\right] d G
$$

Next, recall from the proof of Lemma A.1(a), the definitions of the cost shares of land and labor in the production of consumption goods $j=1,2$ and guns: $\theta_{K j}^{i}=r^{i} a_{K j}^{i} / c_{j}^{i}$ and $\theta_{L j}^{i}=w^{i} a_{L j}^{i} / c_{j}^{i}$, for $j=1,2$; and $\theta_{K G}^{i} \equiv r^{i} \psi_{r}^{i} / \psi^{i}$ and $\theta_{L G}^{i} \equiv w^{i} \psi_{w}^{i} / \psi^{i}$. Then, tedious algebra using equation (A.6) with $p^{i}=\pi$ shows that equation (A.23) can be rewritten as follows:

$$
d M^{i}=\frac{\psi^{i}}{\pi\left|\theta^{i}\right|}\left[\left(1-\alpha_{D}^{i}\right) \theta_{L 1}^{i}+\alpha_{D}^{i} \theta_{L 2}^{i}-\theta_{L G}^{i}\right] d G
$$

where $\left|\theta^{i}\right|=\theta_{K 2}^{i}-\theta_{K 1}^{i}=\theta_{L 1}^{i}-\theta_{L 2}^{i} \gtrless 0$ as $k_{2}^{i} \gtrless k_{1}^{i}$. 
As shown in (A.24), the key in determining the sign of $d M^{i}$ is the sign of the term in brackets, which we denote by $\Lambda^{i}$ :

$$
\Lambda^{i} \equiv\left(1-\alpha_{D}^{i}\right) \theta_{L 1}^{i}+\alpha_{D}^{i} \theta_{L 2}^{i}-\theta_{L G}^{i}
$$

We interpret $\Lambda^{i}$ as reflecting the degree of land intensity of guns production. In particular, if $\Lambda^{i}<0$, then we say that guns production is sufficiently labor intensive; and if $\Lambda^{i}>0$, then we say that guns production is sufficiently land intensive. ${ }^{45}$

To fix ideas suppose that good 2 is produced intensively with land $\left(k_{2}^{i}>k_{1}^{i}\right)$, which implies that $\left|\theta^{i}\right|>0$. In this case, if guns production is sufficiently labor intensive $\left(\Lambda^{i}<0\right)$, then $d M^{i}<0$, implying that there is a positive bias in the export of good 2 relative to the hypothetical case of no conflict. ${ }^{46}$ Alternatively, if guns production is sufficiently land intensive $\left(\Lambda^{i}>0\right)$, then $d M^{i}>0$, implying that there is a positive bias in the import of the land-intensive good. $\|$

Lemma A.7 A country's residual land-labor ratio, $k_{X}^{i}=k_{X}^{i}\left(\pi, B_{F}^{i}\left(G^{j}\right), G^{j} ; \cdot\right)$, will change as follows along its free trade best-response function, $B_{F}^{i}\left(G^{j}\right)$, for $i \neq j$ :

$$
\widehat{k}_{X}^{i}=\frac{\psi^{i}}{R^{i} s_{K}^{i} s_{L}^{i}} \frac{f_{j}^{\prime} f_{i}}{f_{j} f_{i}^{\prime}}\left[\left(\frac{\phi^{i}-\phi^{j}}{2 \phi^{i}-\frac{f_{i}^{\prime \prime} f_{i}}{f_{i}^{\prime 2}}}\right) \theta_{L G}^{i}-s_{L}^{i}\right] d G^{j} .
$$

(a) If $G^{i} \leq G^{j}$, then $d k_{X}^{i} /\left.d G^{j}\right|_{G^{i}=B_{F}^{i}\left(G^{j}\right)}<0$;

(b) If $G^{i}>G^{j}$, then $d k_{X}^{i} /\left.d G^{j}\right|_{G^{i}=B_{F}^{i}\left(G^{j}\right)} \neq 0$ almost always.

Proof: Recall that, since free trade pins down product and, thus, factor prices, $d B_{F}^{i} / d G^{j}=$ $-\phi_{G^{i} G^{j}}^{i} / \phi_{G^{i} G^{i}}^{i}$. Furthermore, observe that country $i$ 's FOC (9) implies (i) $r^{i} K_{0} \phi_{G^{i}}^{i}=\psi^{i}$ and (ii) $r^{i} K_{0} \phi_{G^{j}}^{i}=\psi^{i} \phi_{G^{j}}^{i} / \phi_{G^{i}}^{i}$. Then, these applications of (9) to (A.8) with (A.1)-(A.4) and the simplified expression for $d B_{F}^{i} / d G^{j}$ gives (A.25). Parts (a) and (b) of the lemma follow from (A.25), noting that the coefficient outside the square brackets is positive. Inspection of (A.25) shows further that $d k_{X}^{i} /\left.d G^{j}\right|_{G^{i}=B_{F}^{i}\left(G^{j}\right)}<0$ not only where $G^{i} \leq G^{j}$, but also where $G^{i}>G^{j}$, provided that $\theta_{L G}^{i}$ is not too large relative to $s_{L}^{i}$. Since the expression in square brackets is most likely to be positive when $\phi^{i}=1$ which implies $\phi^{j}=0$ and when $f_{i}^{\prime \prime} / f_{i}^{\prime 2}=0$, a sufficient (but hardly necessary) condition for this derivative to be negative even when $G^{i}>G^{j}$, is that $\theta_{L G}^{i}<2 s_{L}^{i}$. $\|$

\footnotetext{
${ }^{45}$ One can show that these conditions, when evaluated in the autarkic equilibrium, are identical to requiring respectively $k_{G}^{i}(\omega)<k^{i}$ and $k_{G}^{i}(\omega)>k^{i}$.

${ }^{46}$ Note that if the representative country were to export good 2 in the hypothetical case of no conflict, this bias would imply an expansion of the volume of trade under conflict. But, if the country were to import good 2 in the case of no conflict, this bias means that the volume of trade shrinks in the presence of conflict.
} 


\section{Proof of Lemma 3.}

Part (a): The result follows by the definition of $\pi_{A}^{i}$ (which implies $M_{F}^{i *}\left(\pi_{A}^{i}\right)=0$ ) and the observation that the strategic welfare effect-i.e., the second term in the RHS of (11) - is negative (positive) when $k_{2}^{i}>k_{1}^{i}\left(k_{2}^{i}<k_{1}^{i}\right)$.

Part (b): By Lemma 2(b) when $k_{2}^{i}>k_{1}^{i}\left(k_{2}^{i}<k_{1}^{i}\right)$, there exists a sufficiently high (low) price, $\left.\overline{\bar{\pi}}>\pi_{A}^{i}\left(\underline{\underline{\pi}}<\pi_{A}^{i}\right)\right)$, such that $d G_{F}^{j *} / d \pi=0 \forall \pi>\overline{\bar{\pi}}(\forall \pi<\underline{\underline{\pi}})$. But then by (11) and the definition of $\pi_{A}^{i}$, which implies $M_{F}^{i *}(\pi) \lessgtr 0$ for $\pi \gtrless \pi_{A}^{i}$, we must have that, if $k_{2}^{i}>k_{1}^{i}$ $\left(k_{2}^{i}<k_{1}^{i}\right)$, then $d V_{F}^{i *} / d \pi>0 \forall \pi \geq \overline{\bar{\pi}}\left(d V_{F}^{i *} / d \pi<0 \forall \pi \leq \underline{\underline{\pi}}\right)$.

Part (c): By parts (a) and (b), there must exist a price, $\pi_{\min }^{i} \gtrless \pi_{A}^{i}$ when $k_{2}^{i} \gtrless k_{1}^{i}$, that minimizes country $i$ 's welfare while country $i$ exports the land-intensive good. \|

Proof of Proposition 4. Since we consider secure factor distributions in the AES subset of $\mathcal{S}^{0}$, it will necessarily be the case that $p_{A}^{i *}=\widetilde{p}_{A}^{*}$ for $i=1,2$, and thus $\pi_{A}^{i}=\widetilde{p}_{A}^{*}$. For clarity, suppose that $k_{2}^{i}>k_{1}^{i}$; however, keep in mind that analogous results obtain when $k_{1}^{i}>k_{2}^{i}$.

Part (a): By Lemma 3, there thus exists a price $\pi^{i \prime}>\pi_{\text {min }}^{i}$, for $i=1,2$, such that $V_{F}^{i *}(\pi)<$ $\widetilde{V}_{A}^{i *}, \forall \pi \in\left(\widetilde{p}_{A}^{*}, \pi^{i \prime}\right)$. Now define $\pi^{\prime}=\min \left\{\pi^{1 \prime}, \pi^{2 \prime}\right\}$. It follows that $V_{F}^{i *}(\pi)<\widetilde{V}_{A}^{i *}$ for $i=1,2$, $\forall \pi \in\left(\widetilde{p}_{A}^{*}, \pi^{\prime}\right)$.

Part (b): Starting at an arbitrary distribution in the $A E S$ subset of $\mathcal{S}^{0}$, transfer a small quantity of labor from country 2 to country 1 (i.e., $-d L^{2}=d L^{1}>0$ ), so that the final distribution is in the $A E S$ subset of $\mathcal{S}^{1}$. Since in the case of free trade the strategic effect of such transfers vanishes (there is no effect on equilibrium arming), a welfare decomposition similar to that in (A.20) yields $d V_{F}^{1 *} / d L^{1}=-d V_{F}^{2 *} / d L^{1}=\mu(\pi) w(\pi)$. Thus, Lemma A.6(b) implies that $d V_{F}^{1 *} / d L^{1}<d V_{A}^{1 *} / d L^{1}$ and $d V_{F}^{2 *} / d L^{1}>d V_{A}^{2 *} / d L^{1}$. Since $\pi=\tilde{\pi}_{A}^{*}$ implies $V_{F}^{i *}=V_{A}^{i *}$ initially, we will have $V_{F}^{1 *}<V_{A}^{1 *}$ and $V_{F}^{2 *}>V_{A}^{2 *}$ after the transfer. By continuity, there exists additional labor transfers with the just described preferences over trade regimes. $\|$

Proposition A.2 For an asymmetric distribution of secure resources in the AES subset of $\mathcal{S}^{i}$ given world prices in the neighborhood of $p_{A}^{i *}$, country $i$ imports the land-intensive good and is worse off under free trade.

Proof: Consider an allocation in the $A E S$ subset of $\mathcal{S}^{1}$, where $G_{A}^{1 *}>G_{A}^{2 *}$ and $G_{F}^{1 *}=G_{F}^{2 *}$ assuming world prices in the neighborhood of $p_{A}^{1 *}$. Under the maintained assumption that $k_{2}^{i}>k_{1}^{i}, p_{A}^{1 *}>p_{A}^{2 *}$ holds (Lemma $1(\mathrm{~b})$ ). Now suppose, just for the sake of argument, that both countries move to free trade, but face different world prices: $\pi^{1}=p_{A}^{1 *}$ and $\pi^{2}=p_{A}^{2 *}$. The resulting outcome is simply the autarkic equilibrium. To proceed, keep $\pi^{1}=p_{A}^{1 *}$ fixed, 
and suppose that $\pi^{2}$ increases to $\pi^{1}=p_{A}^{1 *}$. This increase in $\pi^{2}$ induces country 2 to increase its arms, which in turn induces country 1 to increase its arms. However, the increase in country 1's arming will be proportionately less, so that in the free trade equilibrium arming is equalized across countries: $B_{F}^{2}\left(G_{F}^{1} ; p_{A}^{1 *}\right)=B_{F}^{1}\left(G_{F}^{2} ; p_{A}^{1 *}\right)>G_{A}^{1 *}>G_{A}^{2 *}$. Assuming that $\theta_{L G}^{1}$ is not too large relative to $s_{L}^{1}$ so that $d k_{X}^{1} /\left.d G^{2}\right|_{G^{1}=B_{F}^{1}\left(G^{2}\right)}<0$ (see equation (A.25)), $\pi^{1}=p_{A}^{1 *}<\pi_{A}^{1}$ and hence country 1's comparative advantage is distorted in this equilibrium: $M_{F}^{1}\left(p_{A}^{1 *}\right)>0$.

Since a shift from autarky to free trade can be viewed as an exogenous change in the effective price, the welfare effects of such a shift can generally be decomposed into the terms of trade effect and the strategic welfare effect as shown in (11). Of course, $\pi^{1}$ has not changed in this experiment, implying the terms of trade effect on country 1's welfare is zero. Thus, the effect of both countries' moving from autarky to free trade on country 1's welfare at $\pi=p_{A}^{1 *}$ will be captured by the negative strategic welfare effect alone (i.e., the second term in equation (11)) induced by the increase in $\pi^{2}$. (Note that, while driven solely by the strategic welfare effect, this adverse consequence for country 1's welfare reflects the distortion in country 1's comparative advantage at $\pi=p_{A}^{1 *}$.)

A fall in the world price below $p_{A}^{1 *}$ induces both a terms of trade improvement and a positive strategic effect for country 1 , and thus causes an increase in country 1's welfare. As such, there exists a world price less than $p_{A}^{1 *}$, for which country 1's welfare under free trade will be equal to that under autarky.

As $\pi$ rises above $p_{A}^{1 *}$ approaching country 1's trade eliminating price $\pi_{A}^{1}$, both the terms of trade effect and the strategic welfare effect for country 1 are negative. Further increases in $\pi$ above $\pi_{A}^{1}$ continue to imply a negative strategic welfare effect, but now also a positive terms of trade effect. Nevertheless, for $\pi$ sufficiently close to $\pi_{A}^{1}$, the former effect will dominate. $\|$

Proof of Lemma 4. To fix ideas let us continue to focus on country 1's incentives, taking as given that country 2 trades freely with ROW. We now write country 1's payoff as $V^{1}\left(p^{1}, G^{1}, G^{2}\right)$ and analyze how this payoff changes as $p^{1}$ increases from $p_{A}^{1}(\pi)$ to $\pi \in$ $\left(\widetilde{p}_{A}^{*}, \pi^{\prime}\right) .{ }^{47}$ The change in welfare identified in this exercise indicates how country 1's payoff changes when the country moves from autarky to free trade, given country 2 chooses free trade. Our analysis proceeds in two steps, first tracing out the welfare consequences of the change in the relative price faced by country 1 from $p_{A}^{1}(\pi)$ to $\pi$ given guns and then tracing out the welfare consequences of the adjustment in guns given that both countries face the

\footnotetext{
${ }^{47}$ Recall, as argued in footnote $38, p_{A}^{1}(\pi)<\pi$ when $\pi>\widetilde{p}_{A}^{*}$.
} 
world price $\pi$.

Step 1: Fix $G^{1}$ and $G^{2}$ at their equilibrium values associated respectively with $p_{A}^{1}(\pi)$ and $\pi$-or equivalently $G_{A}^{1 *}=B_{A}^{1}\left(G_{F}^{2 *}\right)$ and $G_{F}^{2 *}=B_{F}^{2}\left(G_{A}^{1 *} ; \pi\right)$. Hence, our starting point is the equilibrium outcome where country 2 trades freely with ROW and country 1 remains in autarky. Given those equilibrium guns choices, now let $p^{1}$ rise from $p_{A}^{1}(\pi)$ to $\pi$. With this price increase, country 1 becomes an exporter of the non-numeraire good. Given guns, then, the increase in the price faced by country 1 implies an improvement in country 1's terms of trade and, consequently, a higher payoff.

Step 2: Next, fix the relative price faced by both countries at $\pi$, and consider the adjustment in guns by both countries from $\left(G_{A}^{1 *}, G_{F}^{2 *}\right)$ to $\left(G_{F}^{*}(\pi), G_{F}^{*}(\pi)\right)$, the equilibrium guns choices when both countries choose free trade. Note that along this path, guns by each country rise, but $G^{1}<B_{F}^{2}\left(G^{1} ; \pi\right)$ until the equilibrium where both trade freely (with $G^{1}=G^{2}=G_{F}^{*}(\pi)$ ) is reached. Accordingly, given our finding from step 1, it suffices to show that

$$
\frac{d V^{1}\left(\pi, G^{1}, B_{F}^{2}\left(G^{1} ; \pi\right)\right)}{d G^{1}}>0
$$

when $G^{1}<B_{F}^{2}\left(G^{1} ; \pi\right)$.

We assume, for ease of exposition only, that both countries diversify in production. ${ }^{48}$ Since $p^{1}=\pi$, factor prices in the two countries are equalized (i.e., $r^{i}=r$ and $w^{i}=w$ for $i=1,2)$ and $\psi^{i}=\psi$. From equation (8) then, we have

$$
\frac{d V^{1}\left(\pi, G^{1}, B_{F}^{2}\left(G^{1}, \pi\right)\right)}{d G^{1}}=\mu(\pi)\left[r K_{0} \phi_{G^{1}}^{1}-\psi+r K_{0} \phi_{G^{2}}^{1} \frac{\partial B_{F}^{2}\left(G^{1}, \pi\right)}{\partial G^{1}}\right] .
$$

Noting that $\phi_{G^{2}}^{1}=-\phi_{G^{2}}^{2}$ and $\partial B_{F}^{2} / \partial G^{1}=-\phi_{G^{2} G^{1}}^{2} / \phi_{G^{2} G^{2}}^{2}$ while using country 2's FOC for its choice of guns (i.e., $r K_{0} \phi_{G^{2}}^{2}=\psi$ ), allows us to simplify the expression above as follows:

$$
\frac{d V^{1}\left(\pi, G^{1}, B_{F}^{2}\left(G^{1}, \pi\right)\right)}{d G^{1}}=\mu(\pi) \psi\left[\frac{\phi_{G^{1}}^{1}}{\phi_{G^{2}}^{2}}-1+\frac{\phi_{G^{2} G^{1}}^{2}}{\phi_{G^{2} G^{2}}^{2}}\right] .
$$

The first two terms in the square brackets combined reflect the direct, net marginal effect on country 1's payoff from increasing $G^{1}$, whereas the last term reflects the indirect marginal effect of an increase in $G^{1}$ on country 1's payoff through its effect on country 2's guns choice. Using the specification of the conflict technology in equation (1), ${ }^{49}$ these two components

\footnotetext{
${ }^{48}$ Relaxing this assumption would remove the adverse strategic effect of the increase in $G^{1}$ through $B_{F}^{2}\left(G^{1} ; \pi\right)$ on $V^{1}\left(\pi, G^{1}, B_{F}^{2}\left(G^{1} ; \pi\right)\right)$ from our calculations to follow. As such, it would follow immediately that the derivative shown in the expression above is positive.

${ }^{49}$ Also see equations (A.1)-(A.4)
} 
can be written respectively as

$$
\begin{aligned}
\frac{\phi_{G^{1}}^{1}}{\phi_{G^{2}}^{2}}-1 & =\frac{f_{1}^{\prime} f_{2}}{f_{1} f_{2}^{\prime}}-1>0 \\
\frac{\phi_{G^{2} G^{1}}^{2}}{\phi_{G^{2} G^{2}}^{2}} & =-\frac{f_{1}^{\prime} f_{2}}{f_{1} f_{2}^{\prime}}\left[\frac{2 \phi^{2}-1}{2 \phi^{2}-f_{2} f_{2}^{\prime \prime} /\left(f_{2}^{\prime}\right)^{2}}\right]<0 .
\end{aligned}
$$

The inequalities above follow from our assumptions that (i) $G^{1}<B_{F}^{2}\left(G^{1}, \pi\right)$ implying that $\phi^{2}>\frac{1}{2}$ and (ii) $f_{i}^{\prime \prime} \leq 0$ implying that $f_{i}^{\prime} / f_{i}$ is decreasing in $G^{i}$ for $i=1,2$. Thus, (A.27a) shows that the direct effect of an increase in $G^{1}$ on country 1's payoff is positive, while (A.27b) shows that the indirect effect is negative.

As such, to characterize the welfare consequences of the adjustment in guns given the relative price faced by country 1 , we have to dig a little deeper. Specifically, we combine (A.27a) with (A.27b) and simplify, while noting that $2 \phi^{2}-f_{2} f_{2}^{\prime \prime} /\left(f_{2}^{\prime}\right)^{2}>0$, to show

$$
\begin{aligned}
& \operatorname{sign}\left\{\frac{\phi_{G^{1}}^{1}}{\phi_{G^{2}}^{2}}-1+\frac{\phi_{G^{2} G^{1}}^{2}}{\phi_{G^{2} G^{2}}^{2}}\right\} \\
& =\operatorname{sign}\left\{\left[\frac{f_{1}^{\prime} f_{2}}{f_{1} f_{2}^{\prime}}-1\right]\left[2 \phi^{2}-f_{2} f_{2}^{\prime \prime} /\left(f_{2}^{\prime}\right)^{2}\right]-\frac{f_{1}^{\prime} f_{2}}{f_{1} f_{2}^{\prime}}\left[2 \phi^{2}-1\right]\right\} \\
& =\operatorname{sign}\left\{\left[\frac{f_{1}^{\prime} f_{2}}{f_{1} f_{2}^{\prime}}-2 \phi^{2}\right]+\left[\frac{f_{1}^{\prime} f_{2}}{f_{1} f_{2}^{\prime}}-1\right]\left[-f_{2} f_{2}^{\prime \prime} /\left(f_{2}^{\prime}\right)^{2}\right]\right\}
\end{aligned}
$$

The second term inside the curly brackets in (A.28) is non-negative and is strictly positive when $f_{i}^{\prime \prime}<0$. To confirm that the first term is strictly positive, we rewrite it as follows

$$
\frac{f_{1}^{\prime} f_{2}}{f_{1} f_{2}^{\prime}}-2 \phi^{2}=\frac{f_{1}^{\prime} \phi^{2}}{f_{2}^{\prime} \phi^{1}}-2 \phi^{2}=\frac{\phi^{2}}{\phi^{1}}\left[\left(\frac{f_{1}^{\prime}}{f_{2}^{\prime}}-1\right)+\left(1-2 \phi^{1}\right)\right] .
$$

The first term in the square brackets is non-negative since $f_{i}^{\prime \prime} \leq 0$ and $G^{1}<B_{F}\left(G^{1}, \pi\right)$, and the second term is strictly positive since $G^{1}<B_{F}\left(G^{1}, \pi\right)$ implies that $\phi^{1}<\frac{1}{2}$. Hence, country 1's welfare rises under step 2 as well as under step 1 . The same sort of reasoning can be applied to show that country 2 strictly prefers free trade with $\pi \in\left(\widetilde{p}_{A}^{*}, \pi^{\prime}\right]$ to autarky, given that country 1 trades freely with ROW. \| 


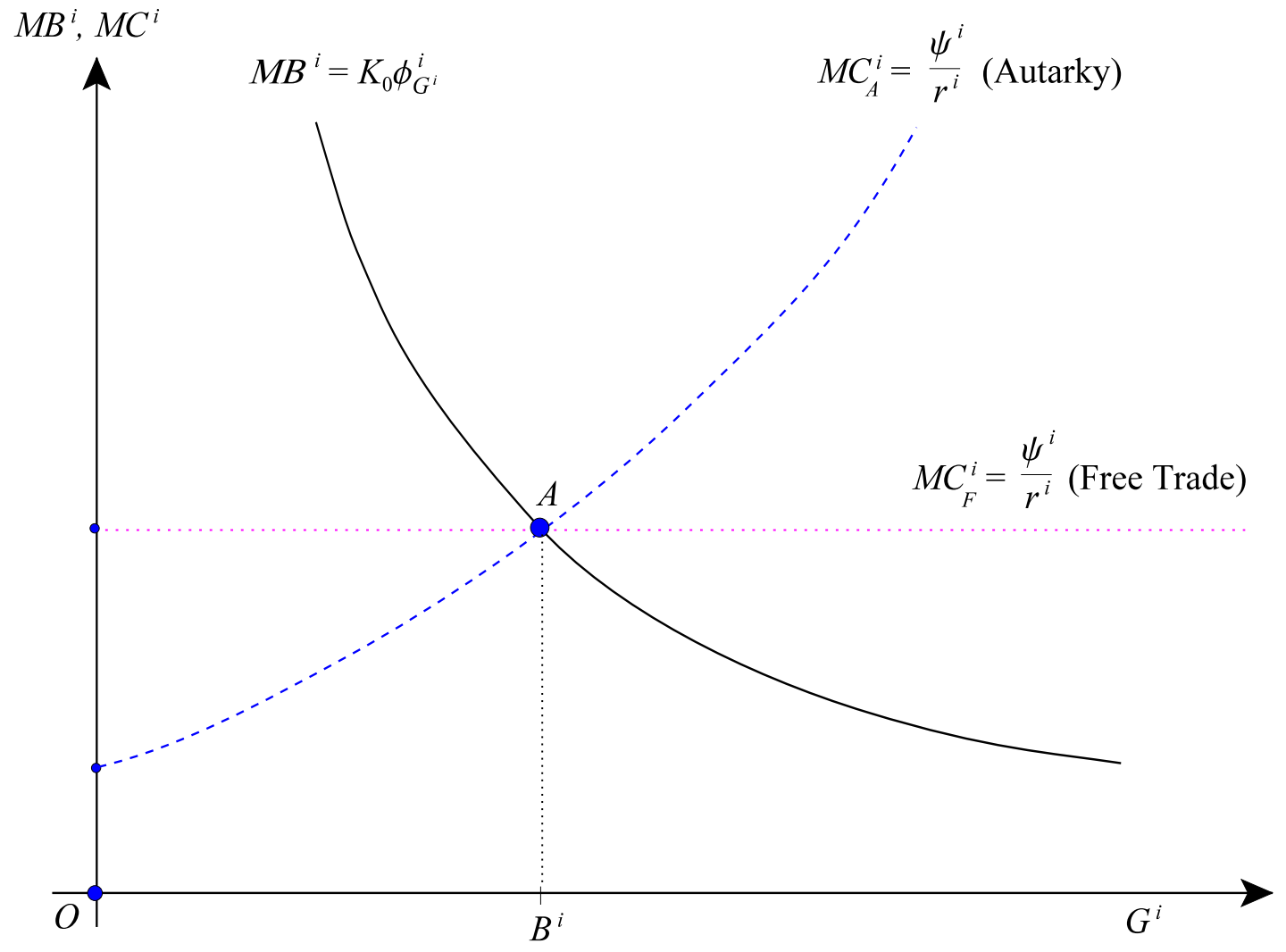

Figure 1

Individually Optimal Security Policies 


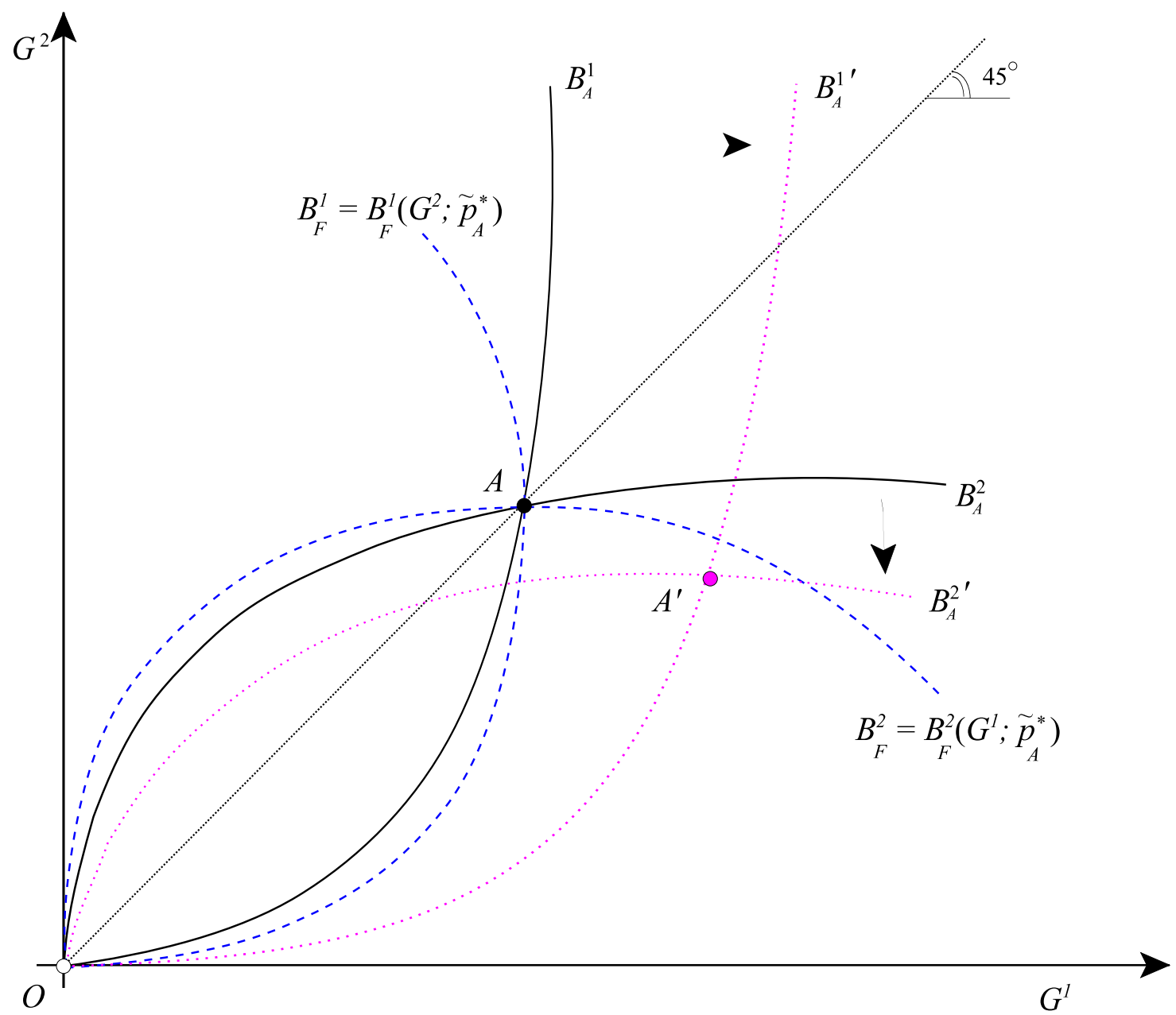

Figure 2

Best-Response Functions in Security Policies 